\title{
Advanced Commercial Liquid-Desiccant Technology Development Study
}

Andy Lowenstein

AIL Research, Inc.

Steven Slayzak, Joe Ryan, and Ahmad Pesaran National Renewable Energy Laboratory

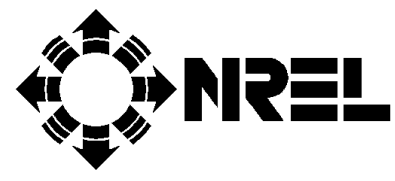

National Renewable Energy Laboratory 1617 Cole Boulevard Golden, Colorado 80401-3393

A national laboratory of the U.S. Department of Energy Managed by Midwest Research Institute for the U.S. Department of Energy under contract No. DE-AC36-83CH10093 


\section{Advanced Commercial Liquid-Desiccant Technology Development Study}

Andy Lowenstein

AIL Research, Inc.

Steven Slayzak, Joe Ryan, and Ahmad Pesaran National Renewable Energy Laboratory

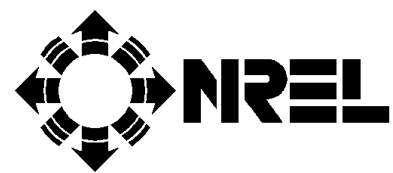

National Renewable Energy Laboratory 1617 Cole Boulevard Golden, Colorado 80401-3393

A national laboratory of the U.S. Department of Energy Managed by Midwest Research Institute for the U.S. Department of Energy under contract No. DE-AC36-83CH10093

Prepared under Task No. BE803001

November 1998 


\section{NOTICE}

This report was prepared as an account of work sponsored by an agency of the United States government. Neither the United States government nor any agency thereof, nor any of their employees, makes any warranty, express or implied, or assumes any legal liability or responsibility for the accuracy, completeness, or usefulness of any information, apparatus, product, or process disclosed, or represents that its use would not infringe privately owned rights. Reference herein to any specific commercial product, process, or service by trade name, trademark, manufacturer, or otherwise does not necessarily constitute or imply its endorsement, recommendation, or favoring by the United States government or any agency thereof. The views and opinions of authors expressed herein do not necessarily state or reflect those of the United States government or any agency thereof.

Available to DOE and DOE contractors from:

Office of Scientific and Technical Information (OSTI)

P.O. Box 62

Oak Ridge, TN 37831

Prices available by calling 423-576-8401

Available to the public from:

National Technical Information Service (NTIS)

U.S. Department of Commerce

5285 Port Royal Road

Springfield, VA 22161

$703-605-6000$ or $800-553-6847$

or

DOE Information Bridge

http://www.doe.gov/bridge/home.html 


\section{Executive Summary}

Applications where solid-desiccant systems are successfully competing can also be served by liquid-desiccant systems (assuming the successful development of critical components); these include applications with large latent loads and/or low dewpoint requirements (e.g., supermarkets, ice rinks, pools, and ventilation air to buildings), applications where high humidity causes property damage (e.g., hotels and storage areas), and applications where high electrical demands can cause problems (e.g., older buildings requiring additional cooling capacity, and buildings with high occupancy but limited usage, such as auditoriums, arenas, and churches). Three technology improvements, zero-carryover, internal cooling, and double effect regeneration will ultimately allow liquid systems to serve expanded markets at lower cost and greater energy savings.

Liquid-desiccant systems for cooling and dehumidifying ventilation air can cost much less than solid-desiccant systems. For example, the manufacturing cost of an evaporatively cooled liquid-desiccant absorber and simple regenerator is about $\$ 0.60$ per cubic foot per minute ( $\mathrm{cfm}$ ) - about half the $\$ 1.20$ per cfm cost for a soliddesiccant rotor and rotary heat exchanger. In fact, with the regenerators that are now available, the liquiddesiccant system will have operating costs comparable to those of the solid-desiccant system; with advanced regenerators, the liquid-desiccant system will have operating costs that are about $40 \%$ lower than those for the solid-desiccant system.

Liquid-desiccant systems using lithium chloride are perceived as requiring more maintenance than soliddesiccant systems. From a market perspective, the carryover of a corrosive desiccant out of the absorber and into the supply ductwork or occupied space is the most important potential problem; an absorber that does not allow liquid desiccant to escape (i.e., a zero-carryover absorber) will bring liquid-desiccant technologies in line with market expectations. However, the state-of-the-art for liquid-desiccant systems, which are now targeted mostly to industrial applications, must be advanced before they can become broadly competitive in heating, ventilating, and air-conditioning (HVAC) applications. One way would be to use such advanced systems on the main recirculation air for buildings. These systems, if successfully developed, could yield major savings in primary energy. A double-effect boiler can provide a superior cooling system primary energy COP; with a double-effect boiler a liquid-desiccant air conditioner in Atlanta will have a seasonal COP of 1.9.

There are several important R\&D needs that must be met before liquid-desiccant air conditioners can begin to fulfill their potential in HVAC applications. Also, additional studies of the competitiveness of the liquiddesiccant air conditioners should be performed to more precisely identify early markets as well as the ultimate potential once the technology matures. In particular, the following items should have high priority:

- Development and demonstration of a zero-carryover, water-cooled absorber

- Development and demonstration of a zero-carryover, evaporatively cooled absorber

- Development and demonstration of a double-effect regenerator for lithium chloride, with special attention to the problems of corrosion and purging.

For each of these components, a manufacturing cost study is needed to accurately determine the first cost for both low and high production volumes. 


\section{Table of Contents}

\section{Part I — Innovations Required to Serve Commercial Markets}

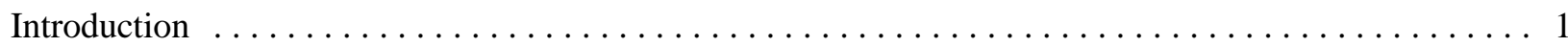

State of the Art for Liquid-Desiccant Technologies $\ldots \ldots \ldots \ldots \ldots \ldots \ldots \ldots \ldots \ldots \ldots \ldots$

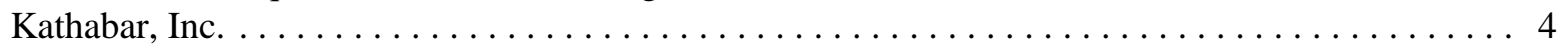

Potential Markets for Liquid-Desiccant Systems $\ldots \ldots \ldots \ldots \ldots \ldots \ldots \ldots \ldots \ldots \ldots \ldots \ldots$

Opportunities for Improving the State of the Art of

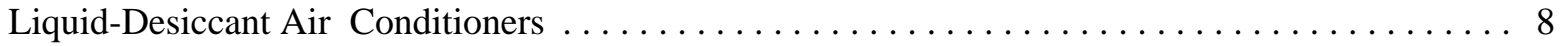

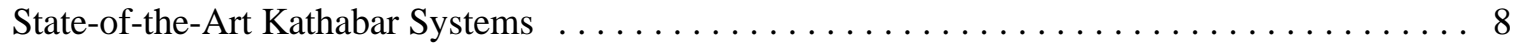

The Need for Low-Flow Zero-Carryover Absorbers $\ldots \ldots \ldots \ldots \ldots \ldots \ldots \ldots \ldots \ldots \ldots$

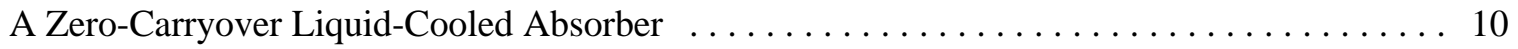

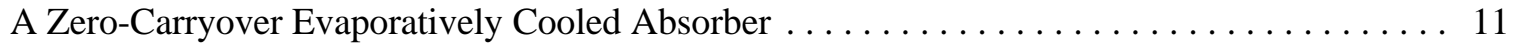

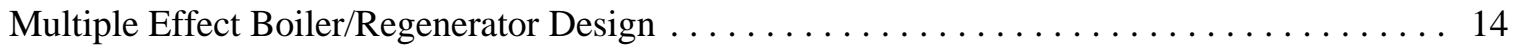

A Double-Effect Regenerator for Liquid Desiccant Systems $\ldots \ldots \ldots \ldots \ldots \ldots \ldots \ldots$

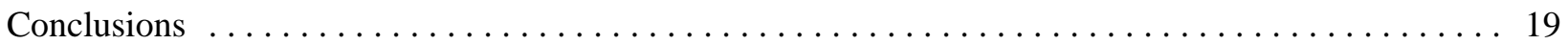

\section{Part II - Energy, Performance, and Cost Analysis}

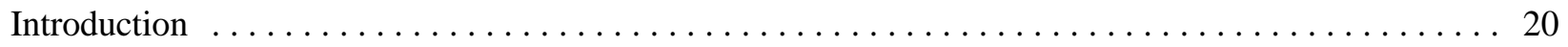

A Comparison of Liquid-Desiccant and Solid-Desiccant Systems Processing Ventilation Air . . . . . 21

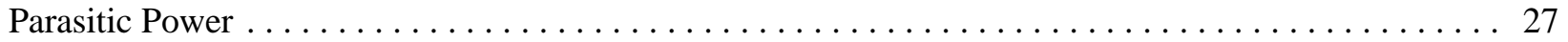

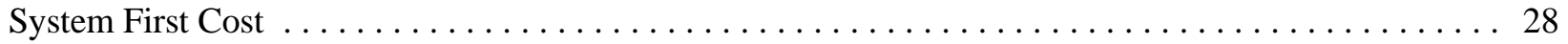

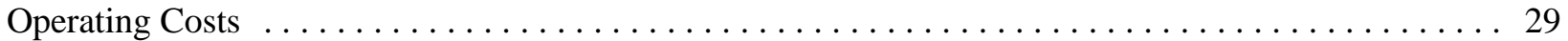

A Comparison of a Liquid-Desiccant System and a

Conventional Vapor-Compression System Processing

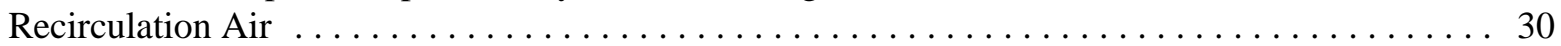

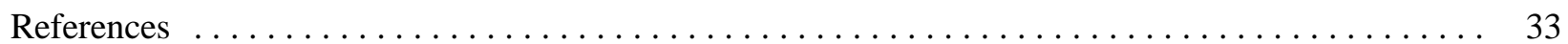

\section{List of Figures}

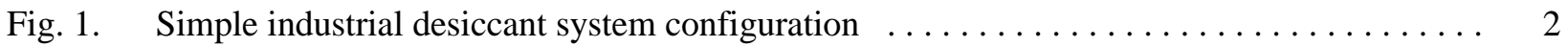

Fig. 2. Kathabar conditioners and regenerators (reprinted with Kathabar's permission) . . . . . . 6

Fig. 3. Single absorber plate with internal flow passages $\ldots \ldots \ldots \ldots \ldots \ldots \ldots \ldots \ldots \ldots \ldots$

Fig. 4. Complete internally cooled, liquid-desiccant absorber $\ldots \ldots \ldots \ldots \ldots \ldots \ldots \ldots \ldots \ldots$

Fig. 5. Theoretical double-effect liquid-desiccant regenerator $\ldots \ldots \ldots \ldots \ldots \ldots \ldots \ldots \ldots \ldots$

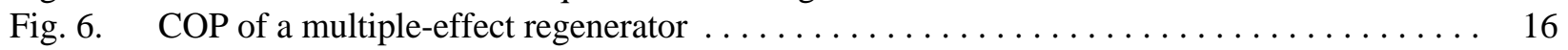

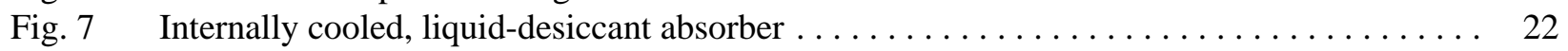

Fig. 8 Schematic of a solid-desiccant system for ventilation air $\ldots \ldots \ldots \ldots \ldots \ldots \ldots \ldots \ldots \ldots$

Fig. 9. Schematic of a water-cooled liquid-desiccant system for ventilation air . . . . . . . . . 24

Fig. 10. Schematic of an evaporatively cooled liquid-desiccant absorber for ventilation air . . . . . 25

Fig. 11. Comparative performance of liquid and solid-desiccant ventilation systems . . . . . . . 26 


\section{List of Tables}

Tab. 1 Kathapac Small Packaged Unit, Conditioner, and Regenerator Engineering Data

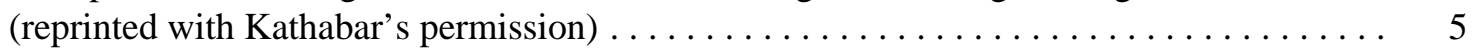

Tab. 2 Price List for Typical Kathabar Systems and Cooling Towers $\ldots \ldots \ldots \ldots \ldots \ldots \ldots \ldots \ldots$

Tab. 3 Liquid Desiccant Air Conditioner Components $\ldots \ldots \ldots \ldots \ldots \ldots \ldots \ldots \ldots \ldots \ldots \ldots$

\section{Appendix}

Appendix A Additional Technology Issues and Opportunities for Further Advancing

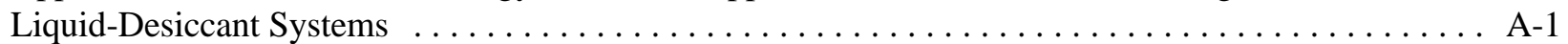

Vapor-Compression Distillation for Desiccant Regeneration . . . . . . . . . . . . A-1 An Engine-Driven Heat Pump Combined with a Liquid-Desiccant Air Conditioner . . . . . . A A-1 A Geothermal Liquid-Desiccant Air Conditioner $\ldots \ldots \ldots \ldots \ldots \ldots \ldots \ldots \ldots \ldots \ldots \ldots$

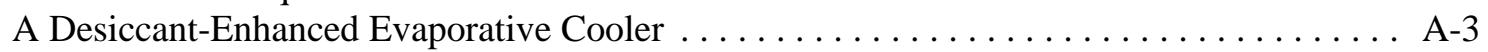

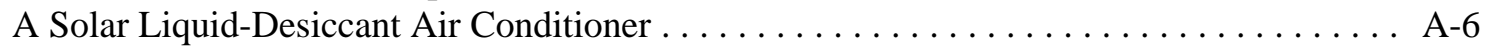

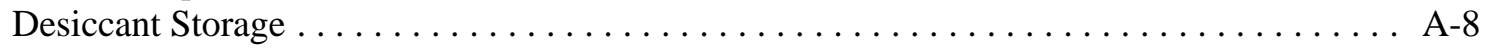

\section{Appendix Figures}

Fig. A-1 Vapor-compression distillation for liquid-desiccant regeneration $\ldots \ldots \ldots \ldots \ldots \ldots$ A-2

Fig. A-2 Schematic of a geothermal liquid-desiccant air conditioner $\ldots \ldots \ldots \ldots \ldots \ldots \ldots \ldots$ A-4

Fig. A-3 Psychrometric performance of a geothermal liquid-desiccant system $\ldots \ldots \ldots \ldots \ldots$ A-5

Fig. A-4 Comparative performance of indirect evaporative cooler and liquid-desiccant system at different outdoor wet-bulb temperatures $\ldots \ldots \ldots \ldots \ldots \ldots \ldots \ldots \ldots \ldots \ldots \ldots \ldots$

Fig. A-5 Drying capability of lithium chloride solutions $\ldots \ldots \ldots \ldots \ldots \ldots \ldots \ldots \ldots \ldots$ A-9 


\section{Part I - Innovations Required to Serve Commercial Markets}

\section{Introduction}

As described in the statement of work for this project, "the multi-year goal of the DOE/NREL Advanced Cooling program is to provide technical support to industry for accelerating the penetration of desiccant cooling technologies into broad commercial building air conditioning markets where their full energy savings potential can be realized." Currently, the U.S. Department of Energy (DOE) is focusing its efforts on soliddesiccant technologies. The manufacturers of solid-desiccant systems have more aggressively pursued commercial heating, ventilating, and air-conditioning (HVAC) applications, therefore, DOE could have a greater immediate impact in this area.

Although now directed more towards industrial applications, liquid-desiccant dehumidification and cooling systems have the long-term potential to save much more energy in HVAC applications than do solid desiccants. These savings result primarily from three factors: (1) the regeneration energy for liquid desiccants can be much lower, (2) air-side pressure drops, and hence parasitic power, will be lower, and (3) evaporative cooling can be more fully exploited.

A simple industrial liquid desiccant system consists of an absorber, also called the conditioner, a regenerator, two pumps, and two heat exchangers (Figure 1). In the absorber, air is cooled and dried as it passes up through packing sprayed with chilled, concentrated liquid desiccant. In industrial terms, this is called the "process" air because it is used by the industrial process requiring dry, cool air. In HVAC terminology, this would be called "supply" air because it is being supplied to the occupied space either directly or through the main air handler. The absorber has mist eliminators on its outlet to prevent droplets of desiccant from leaving with the process air. This is important to conserve desiccant and to prevent a corrosive or otherwise undesirable chemical from entering the ductwork.

In the regenerator, heated desiccant is sprayed down over another packing and scavenger air dries out the desiccant and carries the water, in the form of vapor, outside the building. The regenerator also has mist eliminators to conserve desiccant. In both absorber and regenerator, desiccant dripping from the packing is collected in a sump. A gravity-feed line connects the sumps so water constantly collecting in the absorber sump naturally travels to the regenerator where it can be removed.

The pumps are used to produce the sprays in the absorber and regenerator and drive the desiccant through the heat exchangers. The desiccant flow from the absorber sump to the absorber packing runs through a cooling heat exchanger. Either chillers or evaporative cooling towers can ultimately provide this cooling. The desiccant's ability to collect moisture is typically much greater than its ability to collect heat, therefore the absorber desiccant flowrate is determined by the amount of sensible cooling required by the process air. The regenerator pump serves the same purpose, but it pushes the desiccant through a heating heat exchanger. The desiccant must be heated before it will easily give up its moisture to the scavenger air. In the case of lithium chloride, $200^{\circ} \mathrm{F}$ is a typical regeneration temperature. This is the main energy input driving the dehumidification process, and energy of this relatively low quality can be efficiently obtained from waste heat, natural gas, or solar collectors. A level indicator in the absorber sump controls this energy input. When the level in the absorber sump rises due to increased moisture load, the indicator calls for more energy input at the regenerator to maintain constant dehumidification performance. The regenerator desiccant flowrate is sized to satisfy the maximum expected dehumidification rate required by the process air. The regenerator pump also sends a small flow of concentrated desiccant to the absorber sump, completing the cycle. 


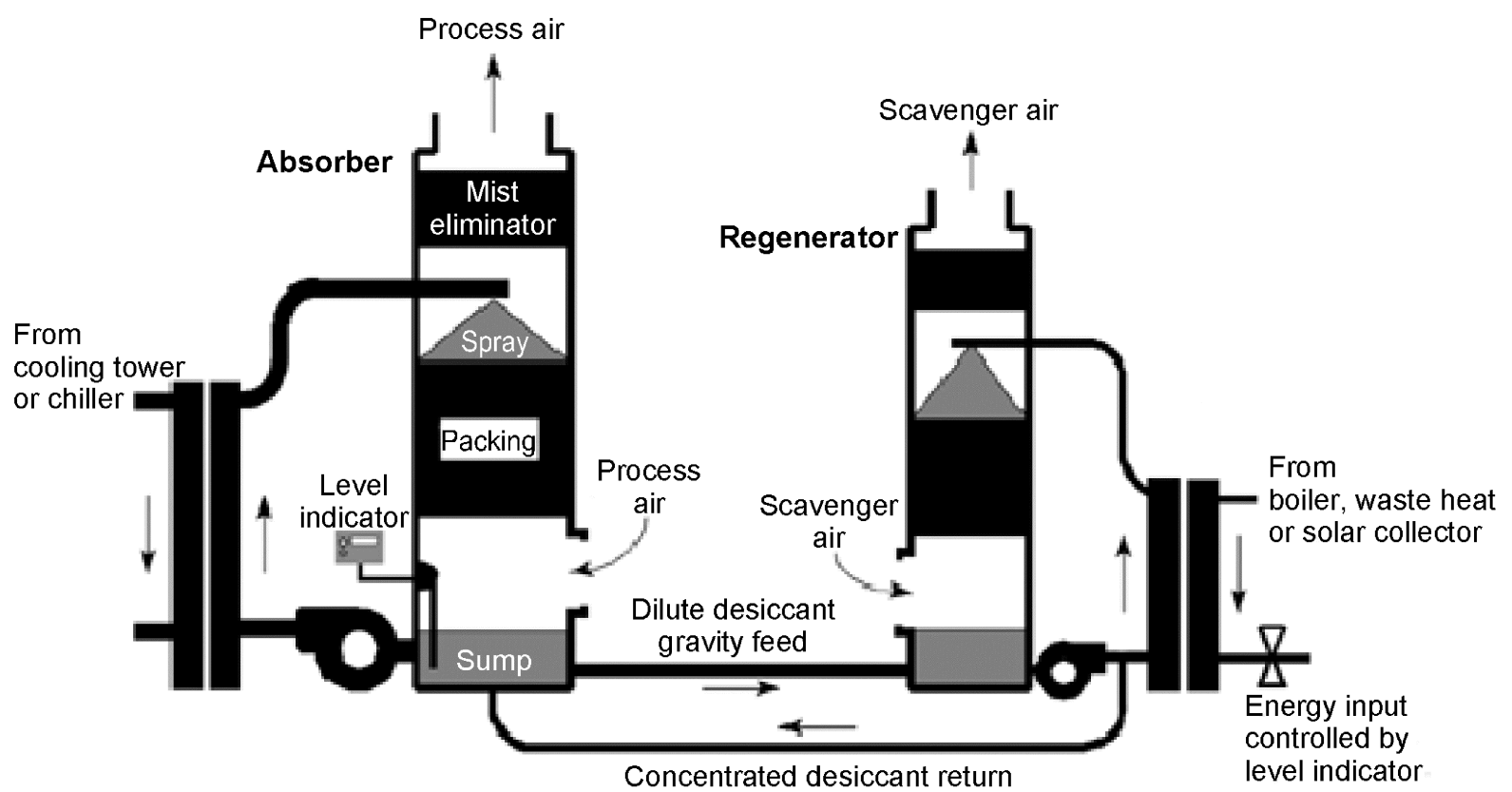

$02468801 \mathrm{~m}$

Figure 1. Simple industrial desiccant system configuration

The objective of this project is to provide information that can help DOE plan its future activities on liquiddesiccant technologies. This objective will be met by (1) identifying commercial and residential markets where the liquid-desiccant systems will first be most successful, and (2) identifying advances in the individual components of a liquid-desiccant system that will allow it to expand into new markets. 


\section{State of the Art for Liquid-Desiccant Technologies}

Although liquid desiccants are occasionally incorporated into commercial HVAC systems (hospitals were a popular application several years ago), they are much more common in industry. Here, they are most useful in either handling very high latent loads, controlling humidity within tight limits, or maintaining very low humidities.

Two manufacturers produce essentially all of the liquid-desiccant equipment in this country: Kathabar, Inc. (P.O. Box 791, New Brunswick, NJ 08903, 732-356-6000), and Niagara Blower Company (673 Ontario Street, Buffalo, NY 14207, 716-875-2000). All Kathabar systems use solutions of lithium chloride as the desiccant, and all Niagara systems use glycols.

There is a third manufacturer of liquid-desiccant systems in the United States-Albers Air Conditioning Corporation (7755 S. Research Drive, Suite 123, Tempe, AZ 85284, 602-820-4280). At recent American Society of Heating, Refrigerating, and Air-Conditioning Engineers, Inc., (ASHRAE) ARI trade shows, it displayed a 2,400-cubic-feet-per-minute ( $\mathrm{cfm}$ ) liquid-desiccant ventilation system that uses solutions that are a mixture of lithium bromide and lithium chloride. Unfortunately, it is difficult to determine whether this system has significant sales.

The use of either lithium chloride or a glycol has an important effect on the liquid-desiccant system's characteristics. The advantage of glycols is that they are much less corrosive than lithium chloride solutions. However, all glycols have significant vapor pressure at regeneration temperatures; this means significant amounts will evaporate into the scavaging air as it carries away the water produced by the dehumidifier. The glycol make-up cost for a regenerator in which hot glycol is sprayed over a packed-bed and a scavenging air stream carries away the water (and some glycol) would be too high for HVAC applications. A research and development (R\&D) project sponsored by New York State Energy Research and Development Authority (NYSERDA) [1] successfully adapted a distillation column for regenerating glycol. This approach greatly limits glycol losses (a 300 parts per million [ppm] concentration was measured in the water from the regenerator), but the process coefficient of performance (COP $)^{1}$ is a relatively low 0.62. Evaporative losses from the absorber can also add cost and represent an unacceptable chemical flow into the occupied space.

Lithium chloride solutions are excellent liquid desiccants because the lithium chloride has essentially zero vapor pressure. These solutions can, therefore, be regenerated at high temperatures with no loss of lithium chloride and cannot evaporate into the supply airstream. Because this also allows the use of a multipleeffect boiler, system COPs for cooling or dehumidification have the potential to be quite high. This report estimates currently practical COPs over 1.0 and predicts that modest innovations needed to apply double effect regeneration to this technology will achieve COPs over 2.0. These values are in line with analyses throughout the literature.

In the past, lithium chloride solutions have had trouble being accepted in HVAC applications because they were perceived as maintenance-intensive. The source of this problem is the corrosivity of the lithium chloride solutions. Of course, one would like a nonvolatile liquid desiccant that was not corrosive. Earlier work has failed to identify a liquid desiccant with these superior properties [2]. However, Kathabar's current generation of equipment replaces much of the metal structure and other metallic components with plastics that are impervious to the lithium chloride.

${ }^{1}$ The COP is defined here as the ratio of the heat needed to boil the quantity of water that has been removed from the salt solution divided by the actual heat to the separation process. 
Therefore, the most important maintenance issue remaining for lithium chloride systems is the possibility of carryover of liquid droplets from the absorber. Work sponsored in part by the Gas Research Institute, shows that a zero-carryover absorber with good performance characteristics is possible [2].

Considering the advantages and disadvantages of glycol and lithium chloride liquid desiccants, this project will focus on the latter. The primary reason for this choice is the extreme difficulty of designing a glycol regenerator that both limits the loss of glycol and has a high efficiency. The corrosion problems presented by lithium chloride can be overcome with relatively modest changes to the design of current technology. In addition, lithium chloride systems can have primary energy COPs considerably higher than 1.0, thus offering substantial energy savings over existing technologies.

\section{Kathabar, Inc.}

In the absense of a credible proposed solution to the glycol evaporation problem, the lithium chloride liquid-desiccant systems manufactured by Kathabar, Inc., provide the best technology base for the development of competitive HVAC equipment. Kathabar sells three small packaged conditioners/ regenerators-240SP, 400SP, and 600SP-with nominal air flows of 2400, 4000 and $6000 \mathrm{cfm}$, respectively. They also make 13 sizes of conditioners with nominal air flows ranging from $2400 \mathrm{cfm}$ to $70,000 \mathrm{cfm}$, and 8 sizes of regenerators with water removal capacities (at $25 \%$ relative humidity conditioned air and $200^{\circ} \mathrm{F}$ regeneration temperature) of $60 \mathrm{lb} / \mathrm{h}$ to $1600 \mathrm{lb} / \mathrm{h}$.

A complete listing of Kathabar's product line appears in Table 1, and representative costs appear in Table 2. Photographs of several Kathabar regenerators and conditioners appear in Figure 2. 
Table 1. Kathapac Small Packaged Unit, Conditioner, and Regenerator Engineering Data (reprinted with Kathabar's permission)

\begin{tabular}{|c|c|c|c|c|c|c|c|c|c|c|c|c|c|}
\hline \multirow{4}{*}{$\begin{array}{l}\text { Unit } \\
\text { Size }\end{array}$} & \multicolumn{4}{|c|}{ Conditioner } & \multicolumn{6}{|c|}{ Regenerator } & \multirow{2}{*}{\multicolumn{3}{|c|}{ Unit Weight, LBS. }} \\
\hline & \multicolumn{2}{|c|}{ Airflow } & \multirow{3}{*}{$\begin{array}{c}\text { Air } \\
\text { Face } \\
\text { Sq. Ft. }\end{array}$} & \multirow{3}{*}{$\begin{array}{l}\text { Nom. } \\
\text { Pump } \\
\text { HP }\end{array}$} & \multicolumn{2}{|c|}{ Airflow } & \multirow{3}{*}{$\begin{array}{c}\text { Air } \\
\text { Face } \\
\text { Sa. Ft. }\end{array}$} & \multirow{3}{*}{$\begin{array}{l}\text { Nom. } \\
\text { Fan } \\
\text { HP }\end{array}$} & \multirow{3}{*}{\begin{tabular}{|c|} 
E.S.P. \\
Avail. \\
in. W.C.
\end{tabular}} & \multirow{3}{*}{$\begin{array}{l}\text { Nom. } \\
\text { Pump } \\
\text { HP }\end{array}$} & & & \\
\hline & & & & & Inlet & Outlet & & & & & \multirow{2}{*}{ Shipping } & \multicolumn{2}{|c|}{ Operating } \\
\hline & CFM & CFM & & & CFM & CFM & & & & & & Normal & Max. \\
\hline $240 S P$ & 1,500 & 3,000 & 6 & 1.5 & 630 & 830 & 2.0 & 1 & 1.9 & 1.5 & 2,400 & 3,300 & 4,400 \\
\hline $400 S P$ & 2,500 & 5,000 & 10 & 1.5 & 950 & 1,260 & 3.2 & 1.5 & 2.0 & 1.5 & 3,300 & 4,400 & 5,900 \\
\hline $6005 P$ & 3,750 & 7,500 & 15 & 2 & 1,480 & 2,000 & 4.7 & 3 & 2.0 & 1.5 & 4,400 & 5,800 & 8,000 \\
\hline
\end{tabular}

CONDITIONER UNITS

\begin{tabular}{|c|c|c|c|c|c|c|c|c|c|c|c|}
\hline \multirow{4}{*}{$\begin{array}{l}\text { Unit } \\
\text { Size }\end{array}$} & \multicolumn{2}{|c|}{ Airflow } & \multirow{4}{*}{$\begin{array}{c}\text { Air } \\
\text { Face } \\
\text { Sq. Ft. }\end{array}$} & \multicolumn{4}{|c|}{ Kathapac FV (Vertical) } & \multicolumn{4}{|c|}{ Kathapac FH (Horizontal) } \\
\hline & \multirow{3}{*}{$\begin{array}{l}\text { Min. } \\
\text { CFM }\end{array}$} & \multirow{3}{*}{$\begin{array}{l}\text { Max. } \\
\text { CFM }\end{array}$} & & \multirow{3}{*}{$\begin{array}{l}\text { Nom. } \\
\text { Pump } \\
\text { HP }\end{array}$} & \multicolumn{3}{|c|}{ Unit Weight, LBS. } & \multirow{3}{*}{$\begin{array}{c}\text { Nom. } \\
\text { Pump } \\
\text { HP }\end{array}$} & \multicolumn{3}{|c|}{ Unit Weight, LBS. } \\
\hline & & & & & \multirow{2}{*}{ Shipping } & \multicolumn{2}{|c|}{ Operoting } & & \multirow{2}{*}{ Shipping } & \multicolumn{2}{|c|}{ Operating } \\
\hline & & & & & & Normal & Max. & & & Normal & Max. \\
\hline 240 & 1,500 & 3,000 & 6 & 2 & 1,300 & 1,950 & 2,600 & - & - & - & - \\
\hline 400 & 2,500 & 5,000 & 10 & 2 & 1,600 & 2,200 & 3,000 & - & - & - & - \\
\hline 600 & 3.750 & 7,500 & 15 & 3 & 2,200 & 3,100 & 4,300 & - & - & - & - \\
\hline 800 & 5.000 & 10,000 & 20 & 5 & 2.000 & 3.900 & 7.000 & 5 & 2.500 & 4,400 & 7.600 \\
\hline 1200 & 7.500 & 15,000 & 30 & 5 & 2,500 & 4,800 & 9.200 & 5 & 3,000 & 5.400 & 9.800 \\
\hline 1600 & 10,000 & 20,000 & 40 & 7.5 & 3,000 & 5,700 & 11,400 & 7.5 & 3,500 & 6,400 & 12,000 \\
\hline 2000 & 12,000 & 24,000 & 48 & 10 & 4,800 & 8,500 & 13,000 & 7.5 & 5,600 & 10,000 & 14,000 \\
\hline 2500 & 15,000 & 30,000 & 60 & 10 & 5,600 & 10,500 & 15,500 & 10 & 6.600 & 11,700 & 16,500 \\
\hline 3000 & 18,000 & 36,000 & 72 & 15 & 6,400 & 12,000 & 18,000 & 10 & 7.600 & 13,700 & 19,500 \\
\hline 4000 & 24,000 & 48,000 & 96 & 15 & 7,900 & 15,000 & 22.500 & 15 & 9.400 & 17,200 & 24,500 \\
\hline 5000 & 30,000 & 60,000 & 120 & 20 & 9,400 & 18,000 & 27,500 & 15 & 11,500 & 19,800 & 29,000 \\
\hline 6000 & 36,000 & 72,000 & 144 & 20 & 10,800 & 21,000 & 32,500 & 20 & 13,100 & 23,300 & 34,000 \\
\hline 7000 & 42,000 & 84,000 & 168 & 25 & 12,400 & 24,000 & 37,000 & 20 & 15,000 & 27,300 & 40,000 \\
\hline
\end{tabular}

REGENERATOR UNITS

\begin{tabular}{|c|c|c|c|c|c|c|c|c|c|}
\hline \multirow{3}{*}{$\begin{array}{l}\text { Unit } \\
\text { Size }\end{array}$} & \multicolumn{2}{|c|}{ Airflow } & \multirow{3}{*}{$\begin{array}{l}\text { Air } \\
\text { Face } \\
\text { Sq. Ft. }\end{array}$} & \multirow{3}{*}{$\begin{array}{l}\text { Nom. } \\
\text { Fan } \\
\text { HP }\end{array}$} & \multirow{3}{*}{$\begin{array}{l}\text { E.S.P. } \\
\text { Avail. } \\
\text { in W.C. }\end{array}$} & \multirow{3}{*}{$\begin{array}{l}\text { Nom. } \\
\text { Pump } \\
\text { HP }\end{array}$} & \multicolumn{3}{|c|}{ Unit Weight, LBS. } \\
\hline & \multirow{2}{*}{$\begin{array}{l}\text { Inlet } \\
\text { CFM }\end{array}$} & \multirow{2}{*}{$\begin{array}{l}\text { Outlet } \\
\text { CFM }\end{array}$} & & & & & \multirow{2}{*}{ Shipping } & \multicolumn{2}{|c|}{ Operating } \\
\hline & & & & & & & & Normal & Max. \\
\hline $1.5 \mathrm{FP}$ & 475 & 630 & 1.5 & 1.5 & 2.4 & 1.5 & 650 & 800 & 1,100 \\
\hline 3FP & 950 & 1260 & 3 & 1.5 & 2.0 & 1.5 & 900 & 1,100 & 1,600 \\
\hline $6 F P$ & 1,900 & 2,520 & 6 & 3 & 1.6 & 2 & 1,200 & 1,650 & 2,300 \\
\hline $10 \mathrm{FP}$ & 3,160 & 4,200 & 10 & 5 & 2 & 5 & 2.100 & 3.300 & 5,000 \\
\hline $15 \mathrm{FP}$ & 4.740 & 6,300 & 15 & 7.5 & 2 & 5 & 2,700 & 4,000 & 6.200 \\
\hline $20 F P$ & 6,320 & 8,400 & 20 & 10 & 2 & 7.5 & 3,400 & 4,800 & 8,000 \\
\hline 30FP & 9,500 & 12,600 & 30 & 15 & 2 & 10 & 4,600 & 6,400 & 11,000 \\
\hline 4OFP & 12,600 & 16,800 & 40 & 20 & 2 & 15 & 5,800 & 8,500 & 14,500 \\
\hline
\end{tabular}

Table 2. Price List for Typical Kathabar Systems and Cooling Towers

\begin{tabular}{|r|r|r|r|r|}
\hline Process Air CFM & Conditioner/Regenerator & $\begin{array}{c}\text { Conditioner/ } \\
\text { Regenerator } \\
\text { Price } \mathbf{( \$ )}\end{array}$ & $\begin{array}{c}\text { Cooling } \\
\text { Tower } \\
\text { Capacity }\end{array}$ & $\begin{array}{c}\text { Cooling } \\
\text { Tower Price } \\
\mathbf{( \$ )}\end{array}$ \\
\hline 6,000 & $600 \mathrm{SP}$ & 60,000 & 30 tons & 4,000 \\
\hline 20,000 & $2000 \mathrm{FV} / 10 \mathrm{FP}$ & 125,000 & 100 tons & 10,000 \\
\hline 70,000 & $7000 \mathrm{FV} / 40 \mathrm{FP}$ & 280,000 & 350 tons & 35,000 \\
\hline
\end{tabular}




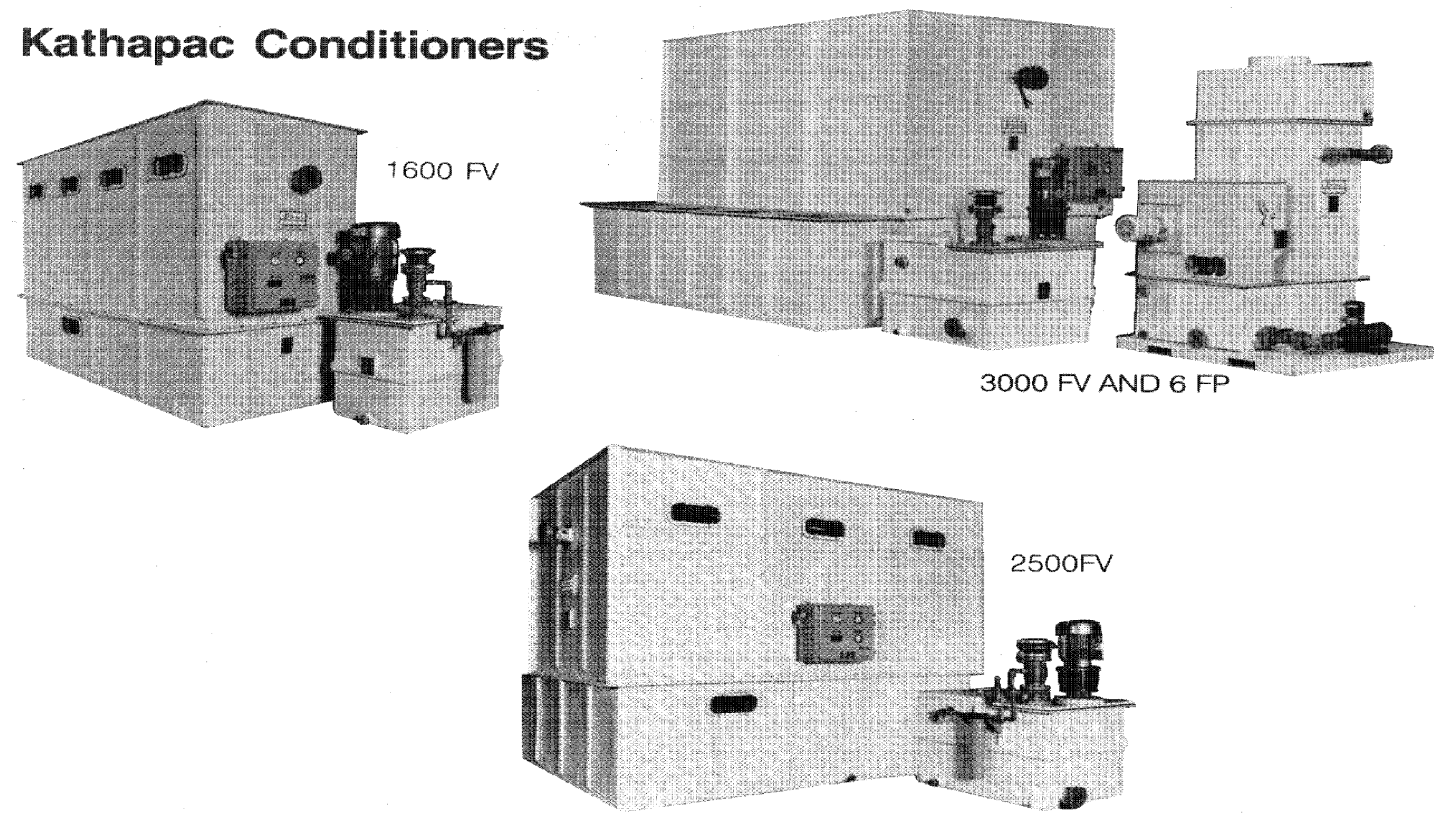

\section{Kathapac Regenerators}
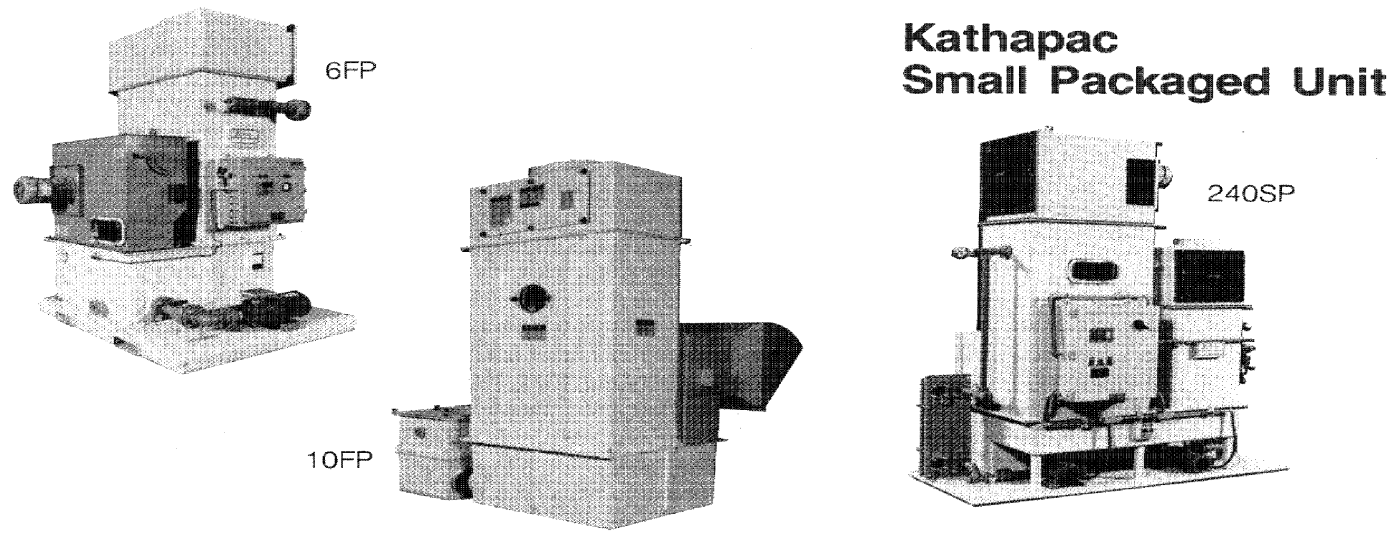

Figure 2. Kathabar conditioners and regenerators (reprinted with Kathabar's permission) 


\section{Potential Markets for Liquid-Desiccant Systems}

Solid-desiccant and liquid-desiccant systems have many similar characteristics. They both dehumidify air by directly absorbing water vapor (as opposed to condensing the water vapor by cooling air to below its dewpoint, as is done with vapor-compression and absorption chiller technologies). Both desiccants are regenerated with heat, which is most commonly provided by a natural gas burner.

Because of their fundamental similarities, liquid-desiccant systems are expected to compete well in applications that have already been targeted by the manufacturers of solid-desiccant systems. This includes applications with the following characteristics:

- Latent loads that are large relative to sensible loads or supply dewpoints must be very low

- Supermarkets

- Ice rinks

- Pools

- Ventilation air to buildings

- High humidity causes significant property damage

- Hotels/motels

- Warehouses and other storage areas

- High electrical demand is difficult to meet

- Older buildings requiring additional cooling

- Buildings with high occupancy, but intermittent usage

(e.g., auditoriums, arenas, and churches)

- Applications that place a very high value on a liquid-desiccant systems' unique ability to suppress microbial growth

- Health field (i.e., hospitals, nursing homes, and health care facilities)

- Food-processing and storage facilities. 


\section{Opportunities for Improving the State of the Art of Liquid-Desiccant Air Conditioners}

The potential exists for liquid-desiccant systems to provide dehumidification and cooling at a lower cost than competing technologies while using less primary energy. However, the current generation of liquid-desiccant systems - which are targeted primarily at industrial applications - do not have the cost, maintenance, and performance characteristics to fully realize this potential.

The following sections briefly describe the state of the art for liquid-desiccant systems. They then describe the technology advances that must be pursued if liquid-desiccant systems are to successfully compete in commercial HVAC applications. In particular, three advances are discussed: (1) a zero-carryover liquid-cooled absorber, (2) a zero-carryover evaporatively cooled absorber, and (3) a double-effect regenerator.

\section{State-of-the-Art Kathabar Systems}

The most significant opportunities for improving the state of the art of liquid-desiccant systems will be in the absorber and regenerator. Using Kathabar's equipment as representative of the state of the art, a typical absorber is composed of a 36-in.-deep bed of structured cellulose packing $\left(125 \mathrm{ft}^{2} / \mathrm{ft}^{3}\right)$. Desiccant is first cooled in a heat exchanger and then sprayed onto the bed at 4 gallons per minute (gpm) per square foot of packingface area. Air flows either upward or across the packing at a face velocity between 250 feet per minute (fpm) and $500 \mathrm{fpm}$ depending on the desired outlet dewpoint.

Kathabar absorbers are constructed from fiber-reinforced plastic (FRP) that resists corrosion from the lithium chloride solution. Because stainless steel will stress-corrode in high chloride environments, cupronickel or titanium is used in the lithium chloride heat exchangers. Other components that come into contact with the lithium chloride solution—e.g., pump impellers, pipes, valves, and nozzles—are mostly made from plastic.

Most Kathabar systems use scavenging-air packed-bed regenerators. As with the absorbers, Kathabar regenerators are constructed from fiber-reinforced plastic. The weak lithium chloride solution is first heated to approximately $200^{\circ} \mathrm{F}$ in a direct-fired cupronickel tubular heater or a steam-to-desiccant heat exchanger. The hot solution is sprayed onto a 36-in.-deep bed of contact media (e.g., Raschig rings) at a rate of approximately 7 to $10 \mathrm{gpm}$ per square foot of packing face area. A scavenging-air stream flows up through the bed at approximately $300 \mathrm{fpm}$. The water vapor that desorbs from the solution at the high temperature is carried out of the regenerator by this scavenging air stream. The regenerator has a COP of between 0.55 and 0.75 .

\section{The Need for Low-Flow Zero-Carryover Absorbers}

Although Kathabar's absorbers provide good performance for the markets that they serve, there are important opportunities to both reduce their cost and improve their performance. Perhaps the most significant limitations are caused by their high desiccant flow rates.

The flow rates in the Kathabar absorbers are set at values that (1) provide good wetting of the packing, and (2) provide sufficient thermal mass to keep the liquid desiccant at a relatively low temperature as heat evolves during absorption. These flow rates, however, compromise performance in several ways:

- Air passages within the packed bed must be fairly wide to prevent the desiccant from restricting the airflow, increasing the size and cost of equipment 
- Because of the desiccant sprays, and the thick desiccant films with free surfaces, air velocities must be low to avoid high-pressure drops and the entrainment of droplets in the air stream, increasing the size and cost of equipment

- Pumps are large and draw considerable power

- The change in desiccant concentration across the absorber is relatively small (e.g., less than one point change in concentration).

Although the first three characteristics clearly limit the absorber's performance (see below), the effect of the fourth is not so obvious. The importance of operating the absorber with a larger desiccant concentration change across it is clear, recognizing that the exchange of desiccant between the regenerator and the absorber imposes two large penalties on the system's performance. For a liquid-desiccant air conditioner that regenerates the desiccant in a simple boiler, with $40 \%$ lithium chloride entering and $44 \%$ lithium chloride leaving it, the energy for preheating the weak desiccant up to the regenerator's operating temperature equals the energy needed to desorb the water vapor. Although a high-effectiveness heat exchanger can greatly reduce the preheating energy, its negative impact on the system's COP is almost always significant. Furthermore, the heat "dumped back" on the absorber by the concentrated desiccant that returns from the regenerator can be a significant fraction of the total cooling provided by the absorber.

One way to reduce these degrading effects is to increase the difference in concentration between the weak desiccant flowing to the regenerator and the strong desiccant returning. As this difference increases, the total flow of desiccant to the regenerator decreases (assuming a constant rate of water removal in the regenerator). This then decreases both the energy needed for preheating and the heat dumped back on the absorber.

In a typical Kathabar system, weak desiccant at $40 \%$ concentration might flow to the regenerator and return at $44 \%$. Because the absorber flooding rate is high compared to the exchange rate between the absorber and the regenerator, the concentration of the desiccant sprayed onto the absorber is only slightly higher than the weak $40 \%$ desiccant.

In a low-flow absorber, the flow rate of desiccant onto the absorber will be comparable to the absorber/regenerator exchanger rate. In this case, the absorber spray concentration will be close to the strong $44 \%$ desiccant. With the stronger initial concentration, the desiccant can be allowed to weaken much more in the absorber and still maintain sufficient cooling and dehumidification. In this example, the desiccant might leave the low-flow absorber at 36\%. The 8-point difference that now exists between the strong and weak desiccants would permit the exchange rate to be cut in half (again for the same total water removal). As noted above, the lower exchange rate significantly improves system performance.

In addition to permitting smaller absorber/regenerator exchanger rates, a low-flow absorber can have much smaller air passages and higher air velocities without creating unacceptably high air-side pressure drops or entraining desiccant in the air stream. A low-flow absorber, therefore, will be much more compact than its high-flow counterpart. This small size can translate into a lower first cost.

The concept of a low-flow absorber was developed in work that AIL Research did for GRI [2]. U.S. Patent No. 5,351,497 defines flow rate limits for the low-flow absorber. However, these low desiccant flows are practical only if the absorber is internally cooled.

There have been at least three attempts to develop an internally cooled absorber [3,4,5]. All past attempts configured the absorber similarly to a parallel-plate, indirect evaporative cooler. The liquid desiccant was sprayed onto the walls of the passages through which the process air flowed, and water was sprayed onto the walls of the passages through which the cooling air flowed. Unfortunately, none of this earlier work 
produced a practical internally cooled absorber. The two biggest problems that were encountered where (1) high air-side pressure drops, and (2) leaks between the cooling and process sides.

All previous work to develop an internally cooled absorber used high flow rates of both desiccant and cooling water. In recent work at AIL Research, small absorbers were successfully operated with the following characteristics:

- Desiccant flows were sufficiently small to produce a 4 to 5 point change in concentration across the absorber compared to the few tenths of a point across a conventional absorber.

- Nominal face velocities were about $400 \mathrm{fpm}$ and the plate-to-plate air gap was $0.10 \mathrm{in} .400 \mathrm{fpm}$ is a typical HVAC face velocity sufficiently high to keep the final product within market size expectations and keep costs down.

- $\quad$ Air-side pressure drops were 0.12" water column (w.c.) for an 8-in-deep absorber compared to 0.5"-1.2" for solid-desiccant rotors under similar conditions.

- The enthalpy effectiveness for an 8-in-deep absorber was 50\%; a 16-in-deep absorber would have an effectiveness of about $75 \% .^{2}$

- No detectable carryover of liquid desiccant out of the absorber.

An internally cooled absorber with the preceding characteristics would be a major advance over today's technology; it would be much more compact and less expensive to manufacture. It would also solve one of the most significant obstacles to the wider acceptance of liquid-desiccant systems: the potential carryover of liquid desiccant out of the absorber.

\section{A Zero-Carryover Liquid-Cooled Absorber}

As previously noted, a liquid-desiccant system for HVAC applications requires a low-maintenance, zero-carryover absorber. Although not now available, a zero-carryover absorber could be developed if the high desiccant flowrates and sprays that are now used in liquid-desiccant systems are replaced by very low flow rates that are distributed directly onto the contact surfaces of the absorber without sprays. However, a low-flow-rate absorber will have a high cooling and dehumidification capacity only if its contact surfaces are internally cooled. Thus, the development of an internally cooled, zero-carryover absorber is critical to the successful commercialization of liquid-desiccant systems for HVAC applications.

Two approaches to internally cooling an absorber are (1) circulate a cooled liquid (e.g., water from a cooling tower or a heat-transfer fluid that has been cooled in a closed evaporative fluid cooler) through internal passages within the absorber, and (2) evaporatively cool the absorber by flowing both air and water through its internal passages. The first option - the liquid-cooled absorber-is the least risky to develop. It does not require that two air streams flow through the same heat exchanger. This greatly simplifies the problem of isolating the process and cooling flows within the absorber.

A liquid-desiccant system that uses a zero-carryover absorber constructed from liquid-cooled plates could have comparable thermal performance, lower parasitic power, and lower first cost than a solid-desiccant system. As shown in the Part 2 report parasitic power is lower for the liquid-desiccant system because air-side pressure

${ }^{2}$ Enthalpy effectiveness, as defined here, is the ratio of the actual change in process air enthalpy divided by the change in enthalpy that would have occurred if the process air left the absorber at equilibrium with desiccant at its inlet concentration and a temperature equal to the inlet cooling water. 
drops are much smaller. In the solid-desiccant system, the process air is first dried in the desiccant wheel and then cooled in the heat exchanger. The total pressure drop is about 1.2" (w.c.). In the liquid-desiccant system, drying and cooling occurs in the same component, so pressure drops are much smaller-approximately onehalf those for the solid-desiccant system.

The integration of drying and cooling in a single component also produces a lower cost absorber. Section 2 of the Part 2 report estimates the manufacturing costs for the liquid-cooled liquid-desiccant absorber to be $\$ 0.64$ per $\mathrm{cfm}$. If a simple, single-effect regenerator is added, the manufacturing cost for the regenerator/absorber subsystem would increase to $\$ 0.77$ per $\mathrm{cfm}$. This cost is much less than the estimated $\$ 1.20$ per cfm manufacturing cost for a solid-desiccant rotor and rotary heat exchanger.

In applications that process ventilation air, the liquid-cooled absorber will also allow the building's intake and exhaust air to be located remotely from each other. (A conventional solid-desiccant system for ventilation air can use the low enthalpy of the exhaust air to improve its performance only if the building's exhaust and ventilation intake are near each other. The liquid-cooled absorber eliminates this constraint because it is possible to use the low-enthalpy exhaust to cool an intermediate heat-transfer fluid that is then pumped to the absorber.)

One approach to a liquid-cooled zero-carryover absorber is now being pursued in this project's third task. This absorber uses plastic plates that are extruded with internal passages. The plates are assembled as shown in Figure 3 to create a serpentine path for the cooling liquid to flow within the plates. A wick is applied to the surface of the plates to evenly distribute the low flow of desiccant over the plate's surface. Individual plates are assembled into a stack as shown in Figure 4. In a typical application, the stack would be located within a duct or cabinet so that the process air flowed through it horizontally.

\section{A Zero-Carryover Evaporatively Cooled Absorber}

The greatest gains in cooling performance efficiency at the lowest capital cost are possible with a zerocarryover absorber that is evaporatively cooled. Although past attempts to develop this type of absorber failed $[3,4,5]$ none tried to exploit low-desiccant flow rates in a zero-carryover design. Assuming that the problems that plagued past work-i.e., high pressure drops and leakage between the cooling and process flows-can be solved in future work, this absorber will have a moderately higher cooling capacity (about 10\% to 15\%) at a lower capital cost (approximately ( $\$ 3,500$ versus $\$ 4,800$ manufacturing cost for a 7500 -cfm unit) compared to a liquid-cooled unit.

An evaporatively cooled absorber is a critical component of a liquid-desiccant cooling system that can compete with vapor-compression equipment in the major market for HVAC systems that condition recirculation air (Section 3 of the Part 2 report). The very close coupling between the cooling and supply air sides of the absorber permit this system to serve the building's entire cooling load even in relatively humid locations (e.g., Atlanta, Georgia). 


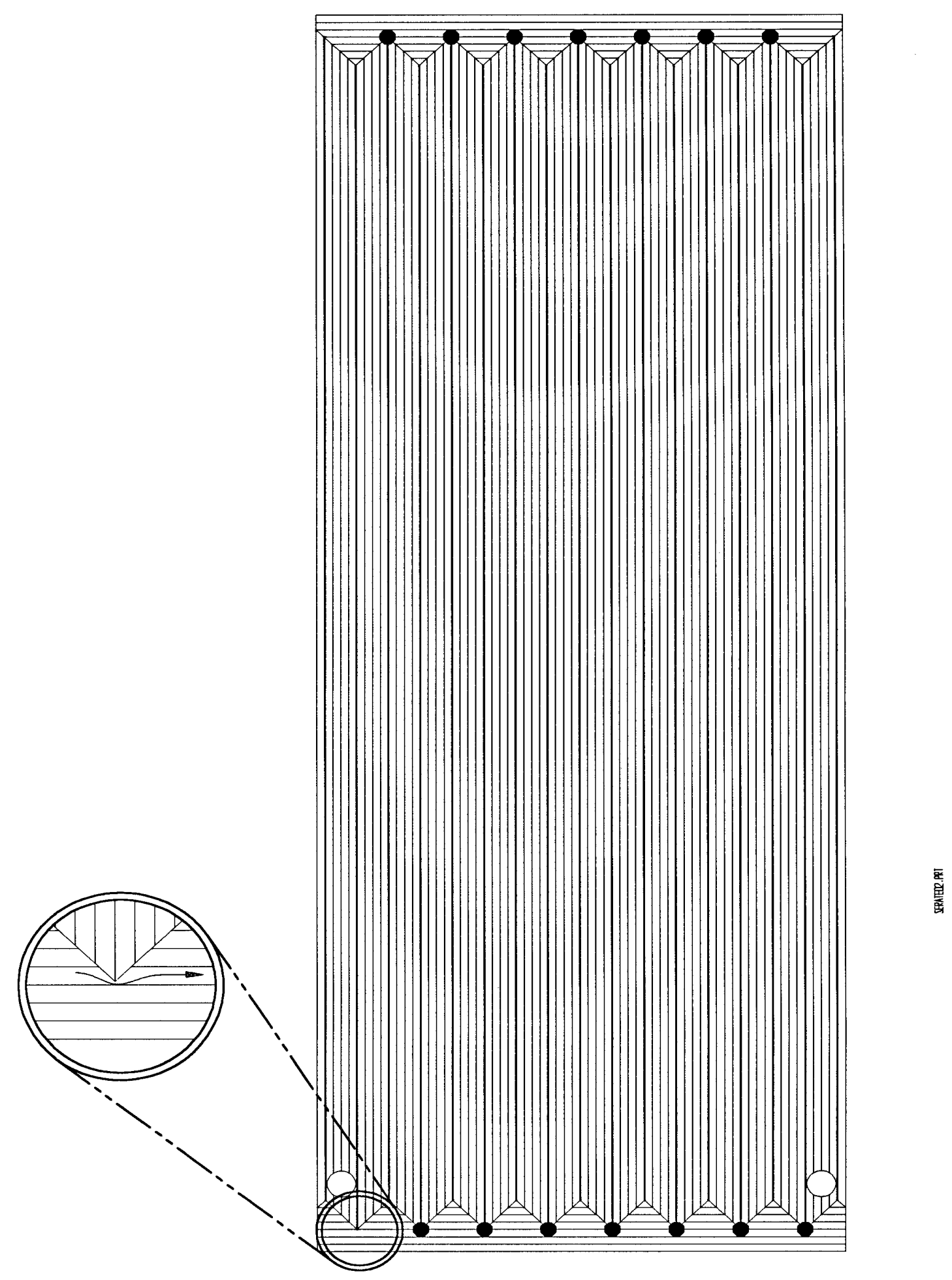

Figure 3. Single absorber plate with internal flow passages 


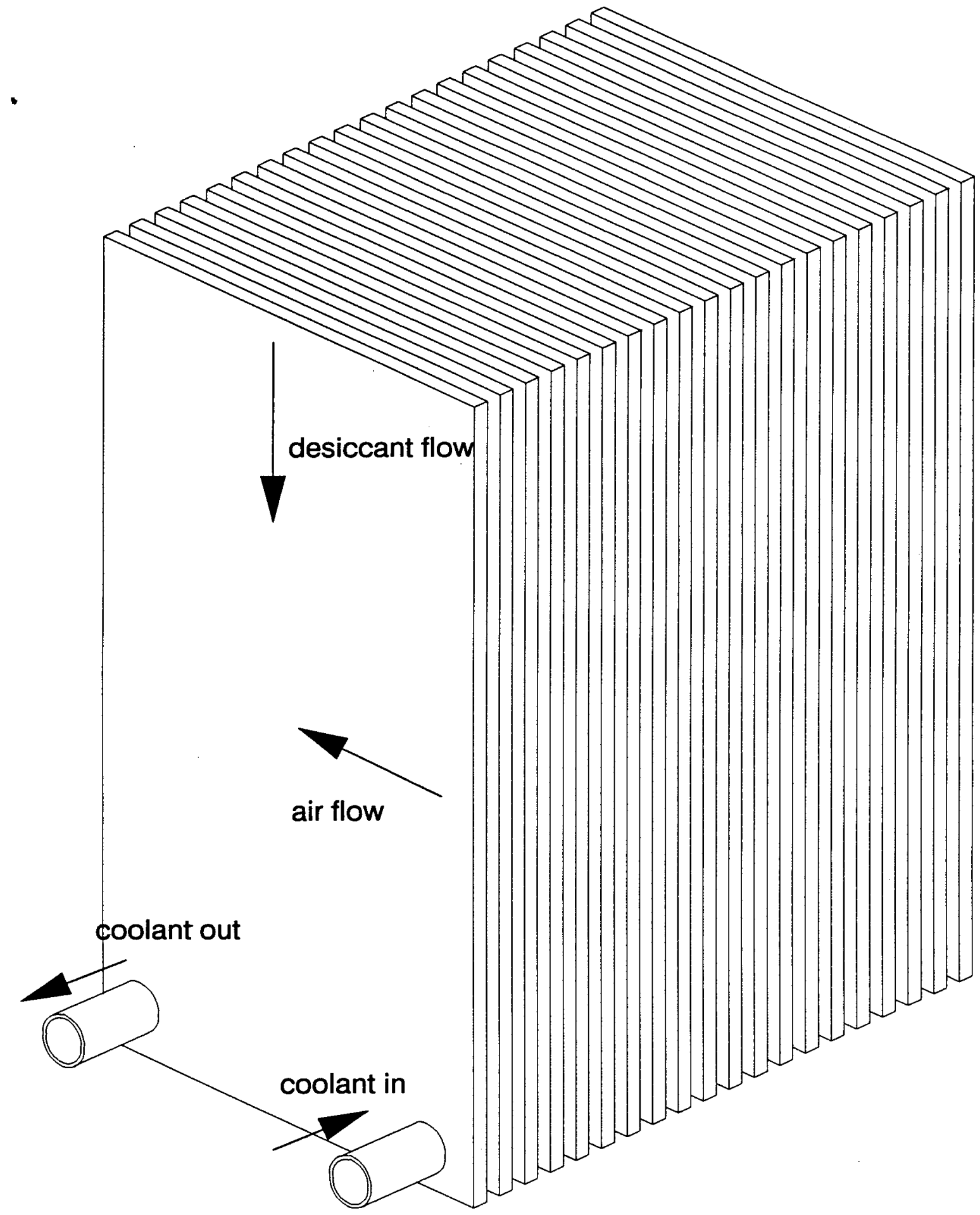

Figure 4. Complete internally cooled, liquid-desiccant absorber 
Evaporatively cooled absorbers can be configured as either cross-flow or counter-flow devices. In a cross-flow configuration, the process air would flow horizontally and the cooling air would flow upward. In the counterflow configuration, the highest COPs would be achieved with the process air flowing downward and the cooling air flowing upward (see footnote 1, page 3).

As with all heat and mass exchangers, the counter-flow configuration will have the highest cooling/ dehumidification effectiveness (for a constant desiccant concentration and absorber surface area). However, ducting the air, desiccant and water flows into and out of a counter-flow absorber is extremely difficult to do without creating unacceptably large pressure drops or leaking fluids between the cooling and process sides. The most prudent approach to developing an evaporatively cooled absorber would be to first focus on the cross-flow configuration.

\section{Multiple Effect Boiler/Regenerator Design}

A liquid-desiccant air conditioner operating on the building's main recirculation air flow can have lower operating costs than a conventional electric vapor-compression unit-when the ratio of electric-to-gas costs based on energy is higher than 3.57 (e.g., gas is less than $\$ 0.69$ per therm when electricity is $\$ 0.084$ per kilowatt-hour $[\mathrm{kWh}])$. Furthermore, liquid-desiccant systems in this application can reduce primary energy use when the combined generation/transmission efficiency for electricity from a fossil power plant is less than $35 \%$. However, these benefits will only be captured if high-efficiency regenerators are developed for liquid desiccants.

When water mixes with a $40 \%$ solution of lithium chloride at a constant temperature and pressure, approximately $100 \mathrm{Btu}$ are released per pound of water. This is the chemical heat of mixing. However, if one were to mix a pound of water in a way that produced work (e.g., use the osmotic pressure to push a piston), the maximum work performed would be less than $100 \mathrm{Btu}$. In this case, the maximum work would equal the change in the Gibbs free energy between the mixed and unmixed states, which is about $20 \%$ lower than the chemical heat of mixing.

If the preceding work-producing mixing is run in reverse, the minimum work needed to run it would again be the change in Gibbs free energy. Because in theory this work could be provided by an ideal heat engine, the minimum heat needed for the separation would be determined by a Carnot engine that converts heat to work. In the limit where the heat is available at a temperature approaching infinity, the heat input to the ideal engine equals the output work. Thus, the minimum heat needed to separate water from the lithium chloride solution equals the change in Gibbs free energy. In this limit, the COP for the separation would be about 12 (see footnote 1, page 3).

The preceding upper bound on the COP for a regenerator is not very useful because it assumes the complete conversion of heat to work. If one assumes that this conversion is $50 \%$ efficient, which is typical of today's most advanced technologies, the limit on COP would be about 6 .

A second approach to bounding the maximum COP for a liquid-desiccant regenerator is to study an ideal multiple-effect boiler in the limit where the number of stages is very large. Multiple-effect boilers are commonly used in industrial separation processes. They achieve high separation efficiencies by using the heat of condensation from vapor in a higher pressure stage to generate additional vapor in a lower pressure stage. 
NON-CONDENSIBLE

HIGH P BOILER LOW P BOILER PUMP

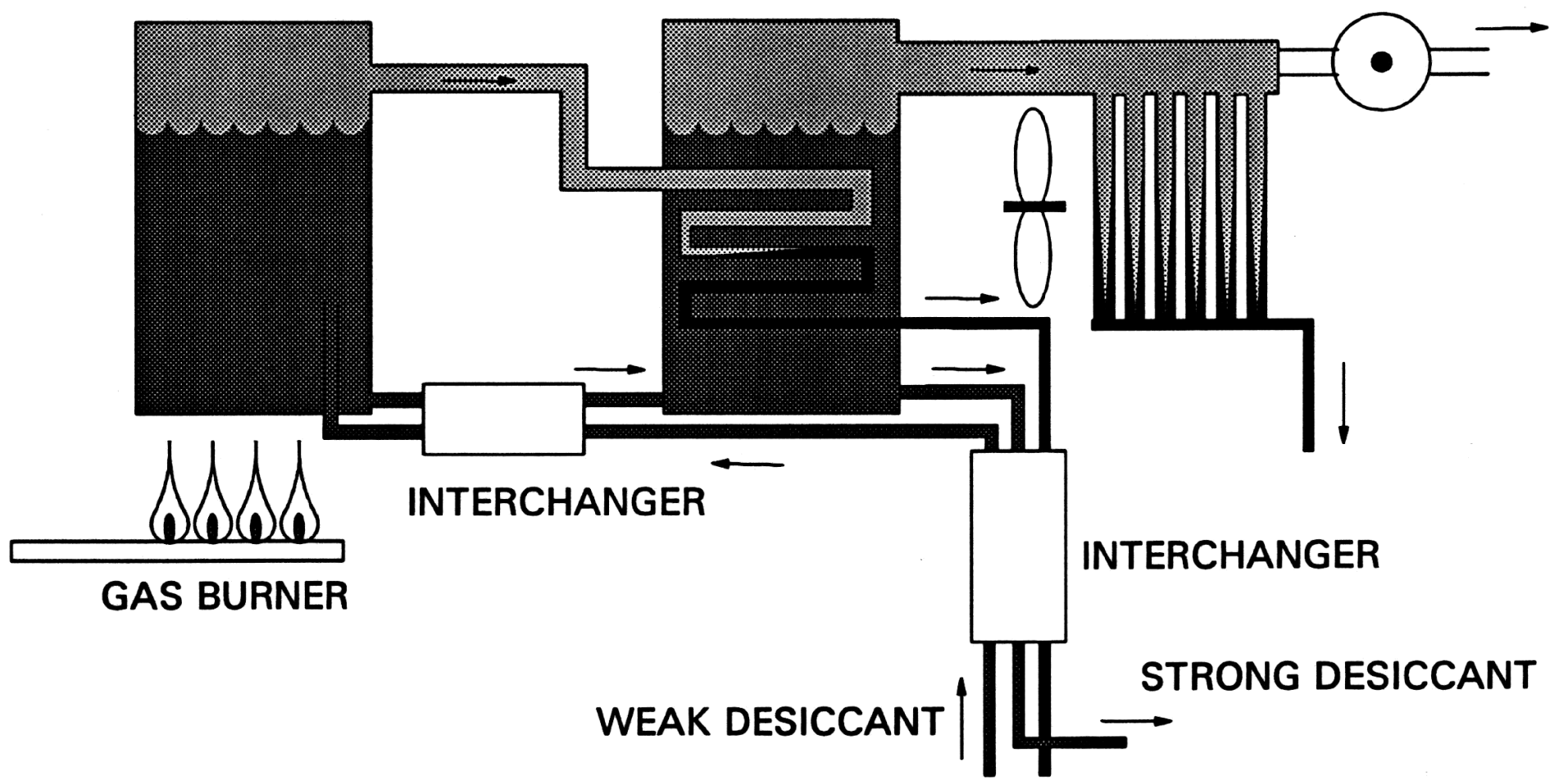




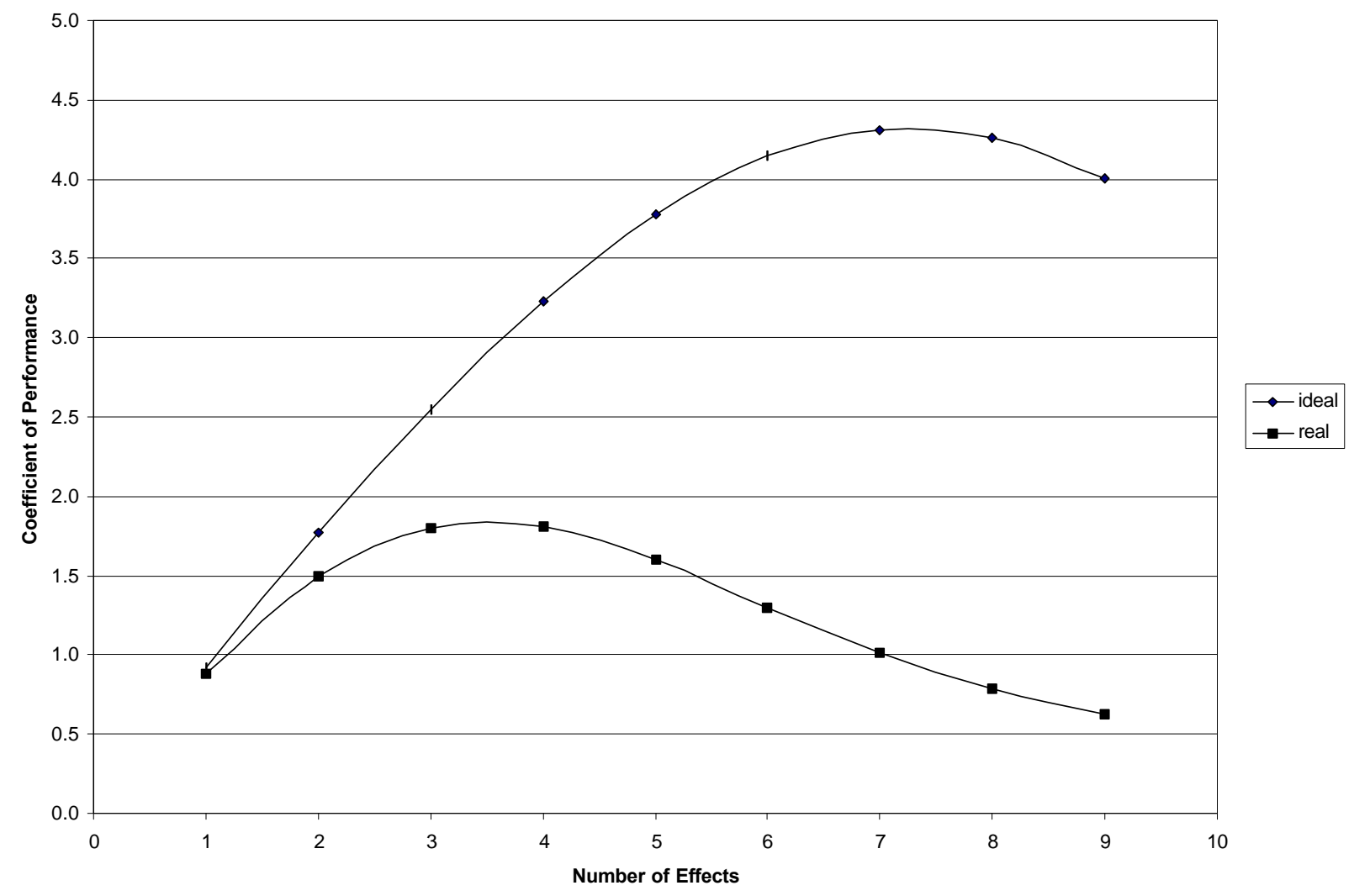

Figure 6. COP of a theoretical multiple-effect regenerator

The theoretical multiple-effect regenerator shown in Figure 5 for two stages was modeled to determine the theoretical limit in regeneration COP offered by these devices. Lithium chloride was concentrated from 39\% to $41 \%$. Heat was recovered from all output streams in "ideal" heat exchangers (e.g., 100\% effectiveness).

Figure 6 shows the ideal COP for the theoretical multiple-effect regenerator as a function of the number of stages. As shown in this figure, the ideal COP reaches a maximum of 4.3 at seven stages.

To understand why the COP for a multiple-effect boiler/regenerator does not continue to increase with the number of stages, one must recognize its two major losses. The most obvious loss is the heat that is rejected as the steam from the lowest pressure stage condenses. This loss always gets smaller as the number of effects increases and less steam is produced in the last stage.

However, a multiple-effect regenerator will also lose heat via the hot concentrated desiccant that leaves it. Although the function of the heat exchangers that are shown in Figure 5 is to minimize this loss by recuperating much of the heat to the weak inlet stream, they cannot completely eliminate it. This is because the combined thermal capacitance of the strong desiccant and the condensate (the two streams leaving the regenerator) will always be greater than the thermal capacitance of the weak desiccant. Thus, the weak desiccant can never cool both the strong desiccant and the condensate down to its inlet temperature.

As the number of stages increase, their average operating temperature increases. This increases the heat loss from the exiting desiccant and condensate streams. At seven stages, the incremental 
increase in this heat loss balances the decrease in the loss from the condensing steam, and the COP reaches a maximum.

The loss from the exiting condensate and desiccant streams will become much greater when the effectiveness of the heat exchangers that recuperate their heat decreases. The curve labeled "real" in Figure 6 assumes a heat exchanger effectiveness of $80 \%$. It also assumes that the condensing temperature of each stage is $7{ }^{\circ} \mathrm{C}$ higher than the boiling point of the next lower one. (The COPs in Figure 6 are based on the heat delivered to the highest stage; they do not account for inefficiencies such as flue losses, which would occur if the heat is provided by a combustion process.)

The COP for the more realistic multiple-effect regenerator peaks at 1.80 for three stages. This COP is $30 \%$ lower than the ideal value for a triple-effect system. For two effects, the "real" COP is 1.5, which is $15 \%$ below the ideal value.

\section{A Double-Effect Regenerator for Liquid Desiccant Systems}

Although double effect regenerators are commonly used in absorption systems, several important issues must be addressed before the technology can be transferred to desiccant systems.

The most important difference between a double-effect boiler for an absorption system and a liquid-desiccant system is that the later must handle a much greater volume of noncondensible gases, including oxygen. This is because the liquid-desiccant system is "open," i.e., the liquid desiccant comes in direct contact with air.

A second "complication" is that the lithium chloride solution that is used in the liquid-desiccant system is incompatible with stainless steels, because they will fail via stress-corrosion cracking in high chloride environments.

There is, however, one important factor that will simplify the design of a double-effect regenerator for liquid desiccants: the peak operating temperature is significantly lower. A $61 \%$ lithium bromide solution, which is typical for an absorption system, has a $105^{\circ} \mathrm{F}$ boiling point elevation. A $43 \%$ lithium chloride solution has only a $75^{\circ} \mathrm{F}$ boiling point elevation. Because both boiler stages will have about a $30^{\circ} \mathrm{F}$ smaller temperature rise, the peak temperature for the liquid-desiccant regenerator will be $60^{\circ} \mathrm{F}$ lower than that for the absorption system. Typical peak temperatures would be $305^{\circ} \mathrm{F}$ and $245^{\circ} \mathrm{F}$ for the absorption and liquid-desiccant regenerators, respectively.

At temperatures of $245^{\circ} \mathrm{F}$ (or lower if the desiccant concentration is kept below 43\%), 70/30 cupronickel is an economical candidate for the high-temperature stage of the liquid-desiccant double-effect regenerator.

Both the upper and lower stages of the liquid-desiccant double-effect regenerator will operate at subatmospheric pressure. A means must therefore be developed for purging the non-condensible gases that will desorb from the desiccant during regeneration.

It is difficult now to design a purge system for a liquid-desiccant regenerator, because data on the solubility of gases in lithium chloride solutions at different temperatures and concentrations is not known. Furthermore, the rate at which gases will absorb and desorb is not known. 
Based on cost data for double-effect regenerators for lithium-bromide absorption chillers, a double-effect regenerator for a liquid-desiccant air conditioner will be a major component of the system's cost (i.e., manufacturing costs for the regenerator and recuperative heat exchangers would be about \$120 per ton). 


\section{Conclusions}

An advanced liquid-desiccant cooling system that processes ventilation air could be a lower cost, higher efficiency alternative to today's solid-desiccant systems. Furthermore, advanced liquid-desiccant systems offer the best option for competing with electric vapor-compression air conditioners in the much larger market for recirculation air systems.

Liquid-desiccant systems that use solutions of halide salts have the most acceptable operating characteristics for HVAC applications. However, these systems are extremely sensitive to the maintenance that would be needed if there is even a slight amount of desiccant carryover out of the absorber. Therefore, a zero-carryover absorber must be developed before liquid-desiccant systems can realize their potential in HVAC applications.

The most viable approach to developing a zero-carryover absorber is to work at much lower desiccant flooding rates than are now used in industrial liquid-desiccant systems. Absorbers with desiccant flooding rates that are more than an order of magnitude less than now used are practical if (1) the absorber is internally cooled and (2) the absorber surfaces use a wick to distribute the desiccant.

The most efficient liquid-desiccant systems will need advanced regenerators that have yet to be developed. Double-effect regenerators - which are standard equipment for lithium-bromide absorption chillers - are the most promising candidate for a near-term, high-efficiency regenerator for liquid desiccants. 


\section{Part II - Energy, Performance, and Cost Analyses}

\section{Introduction}

This is the second of two task reports under the "Advanced Liquid Desiccant Technology for Commercial Markets" scoping study. This report provides supporting analyses for the technology improvements that are needed to expand liquid-desiccant technology beyond its current industrial base into heating, ventilation, and air-conditioning (HVAC) applications. The report focuses on two important applications: (1) the conditioning of a building's ventilation air, and (2) the conditioning of a building's main recirculation air. Secondary technical issues and novel applications that could serve as important early niche markets are discussed in Appendix A. 


\section{A Comparison of Liquid-Desiccant and Solid-Desiccant Systems Processing Ventilation Air}

In many climates, ventilation air imposes very high latent loads on buildings. Conventional vapor-compression systems cannot effectively handle these loads, but solid-desiccant systems are increasingly successful in this market. Does a liquid-desiccant system designed to process ventilation air offer any advantages over a soliddesiccant system? Modeling both systems under the same operating conditions indicates that it does. This modeling also shows an evaporatively cooled absorber delivers a higher cooling capacity and system coefficient of performance (COP) than a liquid-cooled absorber.

The theoretical liquid-desiccant system modeled here differs significantly from the state of the art (i.e., Kathabar's absorbers and regenerators). The Gas Research Institute's (GRI's) Final Report [2] shows that the efficiency of a liquid-desiccant system can be significantly improved by reducing the desiccant flooding rate to less than one-tenth the values now used in industrial equipment. Furthermore, very low flooding rates can reduce, or possibly eliminate, carryover of liquid desiccant out of the absorber.

Because high efficiency and negligible carryover are crucial to the success of liquid-desiccant systems in both commercial or residential HVAC markets, all modeling work presented here assumes low-flow absorbers. However, a low-flow absorber must be internally cooled [2]. (It is not possible to first chill the desiccant and then bring it in contact with the process air in an adiabatic packed bed, because the desiccant will not have sufficient thermal capacitance.)

Internally cooled absorbers with either DX or chilled water coils that also served as the desiccant/air contact surface have been applied in the past. However, these absorbers are too expensive to be part of a competitive liquid-desiccant system for HVAC ventilation air. The approach taken in this study was to model the liquiddesiccant system using one of two cooled absorbers each employing a different internal cooling approach (neither of which have been proven at full scale).

The first absorber is cooled internally by a heat-transfer fluid. The cooling source can be a conventional cooling tower or a "closed" evaporatively cooled fluid cooler. The absorber, Figure 7, is composed of a stack of plastic plates. Each plate has an internal fluid circuit. (A 1,000-cubic-feet-per-minute [cfm] model of this absorber was delivered to the National Renewable Energy Laboratory [NREL] in September 1998 as part of this project.) Desiccant is delivered to the top of each plate at a very low flow rate-typically about 0.15 gallons per minute (gpm) per square foot of frontal face area of the plate stack. Thin wicks attached to the surface of the plates distribute the desiccant evenly over the surface. The process air flows horizontally through the absorber. Approximately 0.1 to $0.2 \mathrm{gpm}$ of cooling water flows within each plate. Water consumption from evaporation and "blowdown" is comparable to that for a conventional evaporative cooling system: on the order of 2 gallons per hour (gph) per ton of cooling.

The second absorber uses evaporative cooling within the absorber's plates. This absorber is very similar to a parallel-plate indirect evaporative cooler that has been modified so that films of liquid desiccant flow down the plates in contact with the process air.

GRI has attempted to develop an evaporatively cooled absorber in at least three projects $[3,4,5]$. Two of the three projects produced working models of the absorbers. Unfortunately, neither model was successful. The most significant problems were (1) leaks between the process and cooling sides of the absorber and (2) flooding of the air passages with liquid, which produced high pressure drops and carryover. 


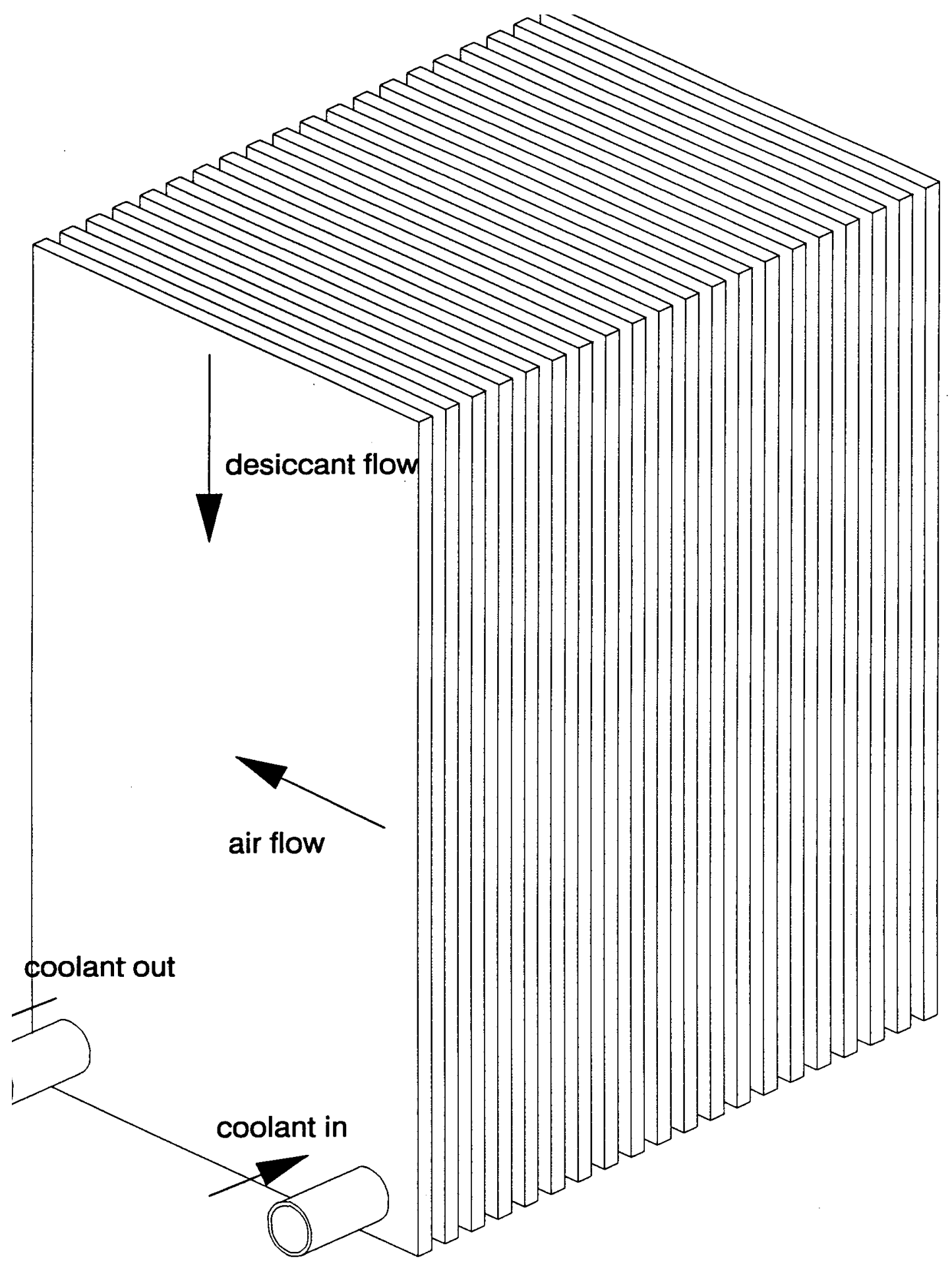

Figure 7. Internally cooled, liquid-desiccant absorber. 
Both the solid-desiccant and liquid-desiccant ventilation air systems are designed for the following design-day conditions:

$7,500 \mathrm{cfm}$ exhaust air at $80^{\circ} \mathrm{F}, 50 \%$ relative humidity

$7,500 \mathrm{cfm}$ ventilation air at $95^{\circ} \mathrm{F}, 50 \%$ relative humidity

(Indoor conditions are the same as the Air Conditioning and Refrigeration Institute [ARI] summer rating point; outdoor conditions have the same dry-bulb temperature as the ARI summer rating point but are considerably more humid: $0.0178 \mathrm{lb}_{\text {water }} / \mathrm{lb}_{\text {air }}$ versus $0.0141 \mathrm{lb}_{\text {water }} / \mathrm{lb}_{\text {air }}$ at ARI.)

The solid-desiccant ventilation air system that was modeled is shown in Figure 8. GRI's DESSYS2 computer program was used to calculate the system's performance. A silica-gel rotor with the same matrix properties as the one used in Reference 6 (p.78) was modeled. The rotor was sized so that it processed 7,500 cfm with a face velocity of 540 feet per minute (fpm). The regeneration angle was set to $90^{\circ}$. The process/regeneration airflow ratio was 3.9. The rotor diameter was 60 inches. At each regeneration temperature, the rotor speed was adjusted so that maximum cooling capacity was achieved. The desiccant system also included a $90 \%$ effective air-to-air heat exchanger and a $90 \%$ effective saturator. The heat exchanger was a rotary type, and its characteristics are based on data in Collier's report to the U.S. Department of Energy [6].

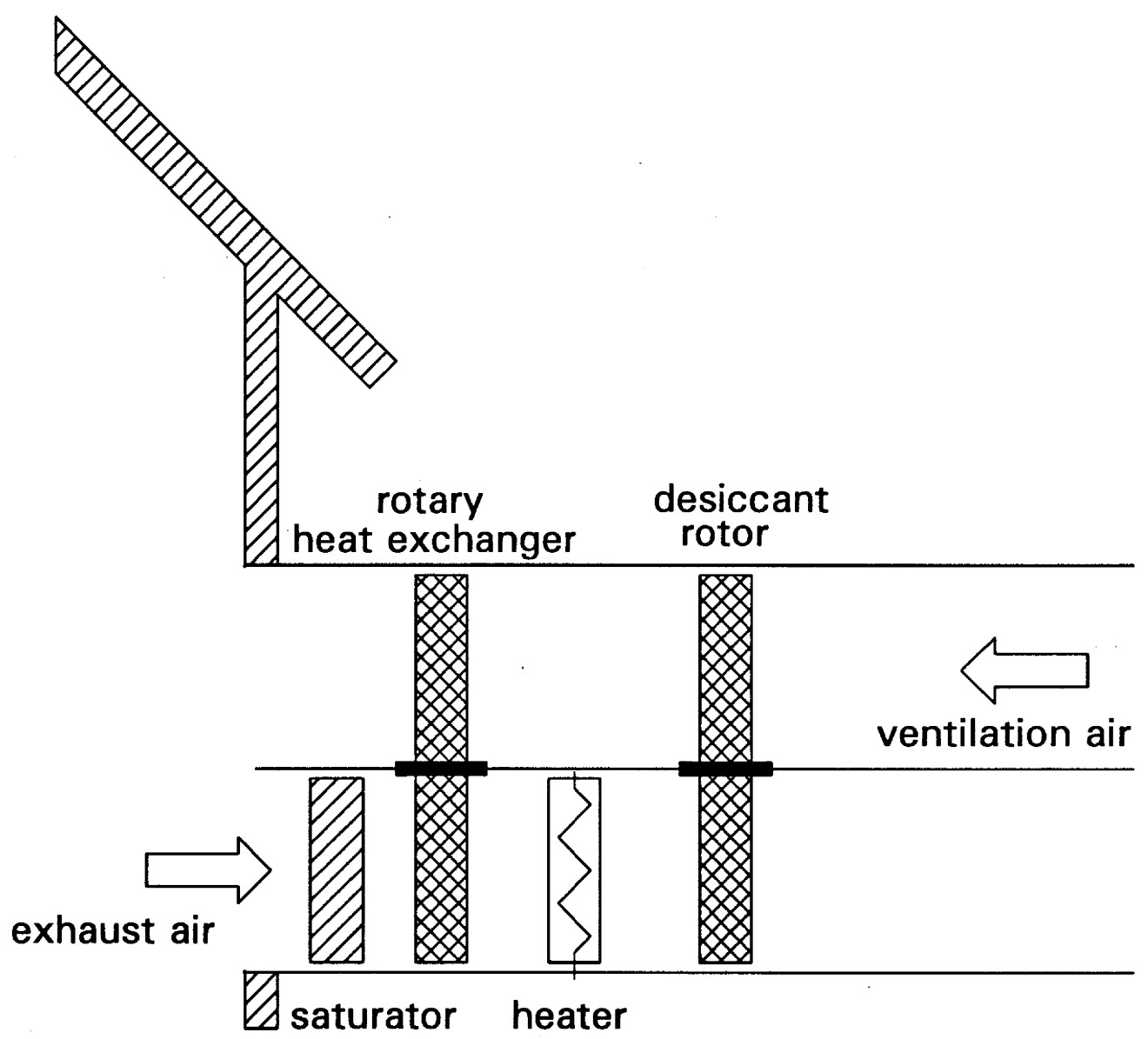

Figure 8. Schematic of a solid-desiccant system for ventilation air. 
Figures 9 and 10 show the two liquid-desiccant systems that were modeled; the first system uses a liquidcooled absorber and the second, an evaporatively cooled absorber. The liquid-cooled absorber is assumed to be made from plastic plates and to have the following characteristics:

$\begin{array}{ll}\text { plate height } & 33 " \\ \text { plate depth } & 16^{\prime \prime} \\ \text { plate thickness } & 0.10^{\prime \prime} \\ \text { number of plates } & 413 \\ \text { air gap } & 0.10^{\prime \prime} \\ \text { stack width } & 81 "\end{array}$

As thown in Figure 9, the coolant for the absorber is provided by a "closed" evaporatively cooled fluid cooler. This fluid cooler is identical to the absorber except that water flows down the wicked-plate surfaces instead of desiccant. Cooling air, in this case the exhaust air from the building, flows horizontally through the stack of plates. As the water evaporates, heat is removed from the fluid flowing within the plates. This water cooling function could also be performed by a conventional chiller for increased capacity at higher energy cost. This analysis is not provided here.

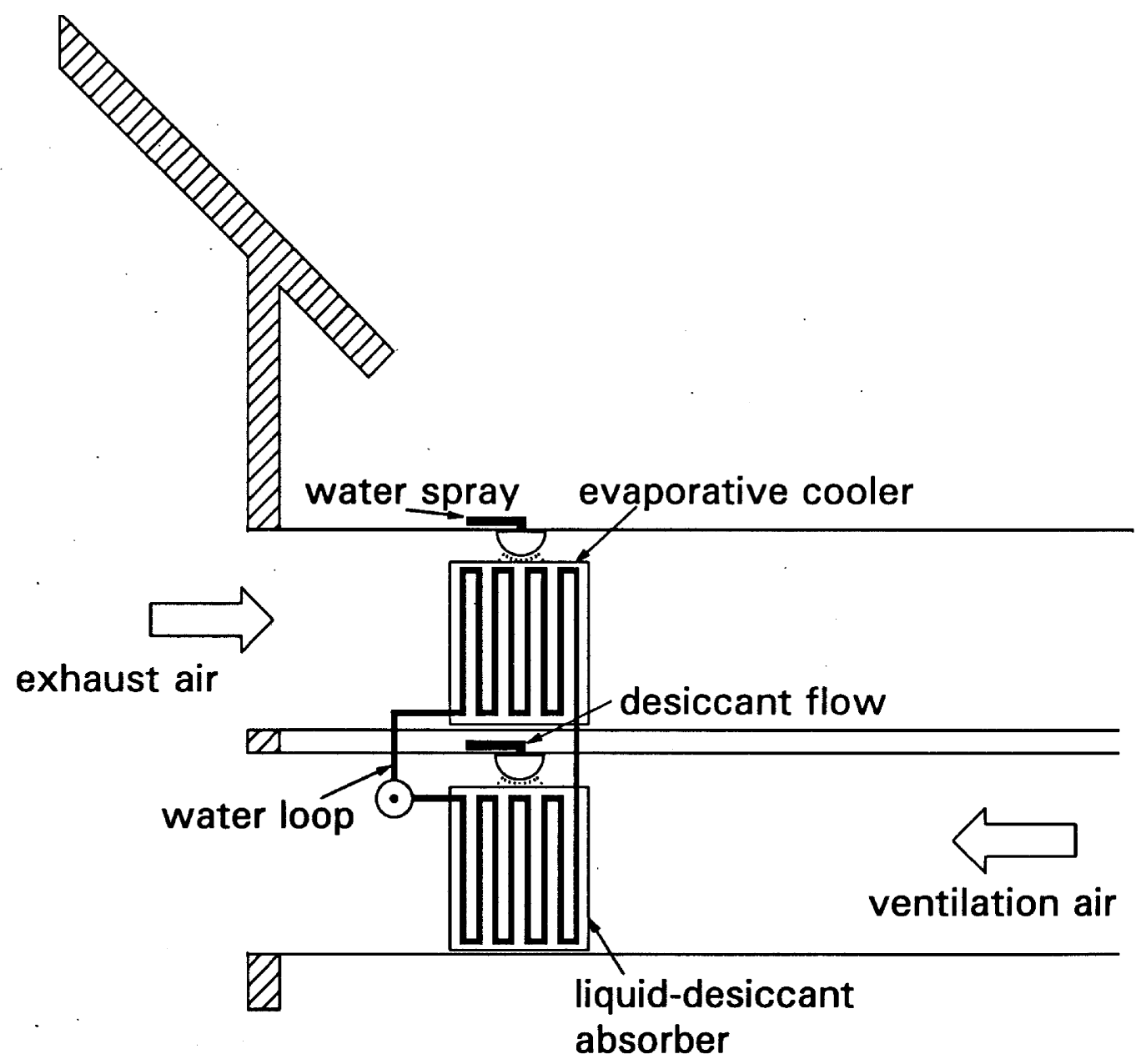

(regenerator not shown)

Figure 9. Schematic of a water-cooled liquid-desiccant absorber for ventilation air. 


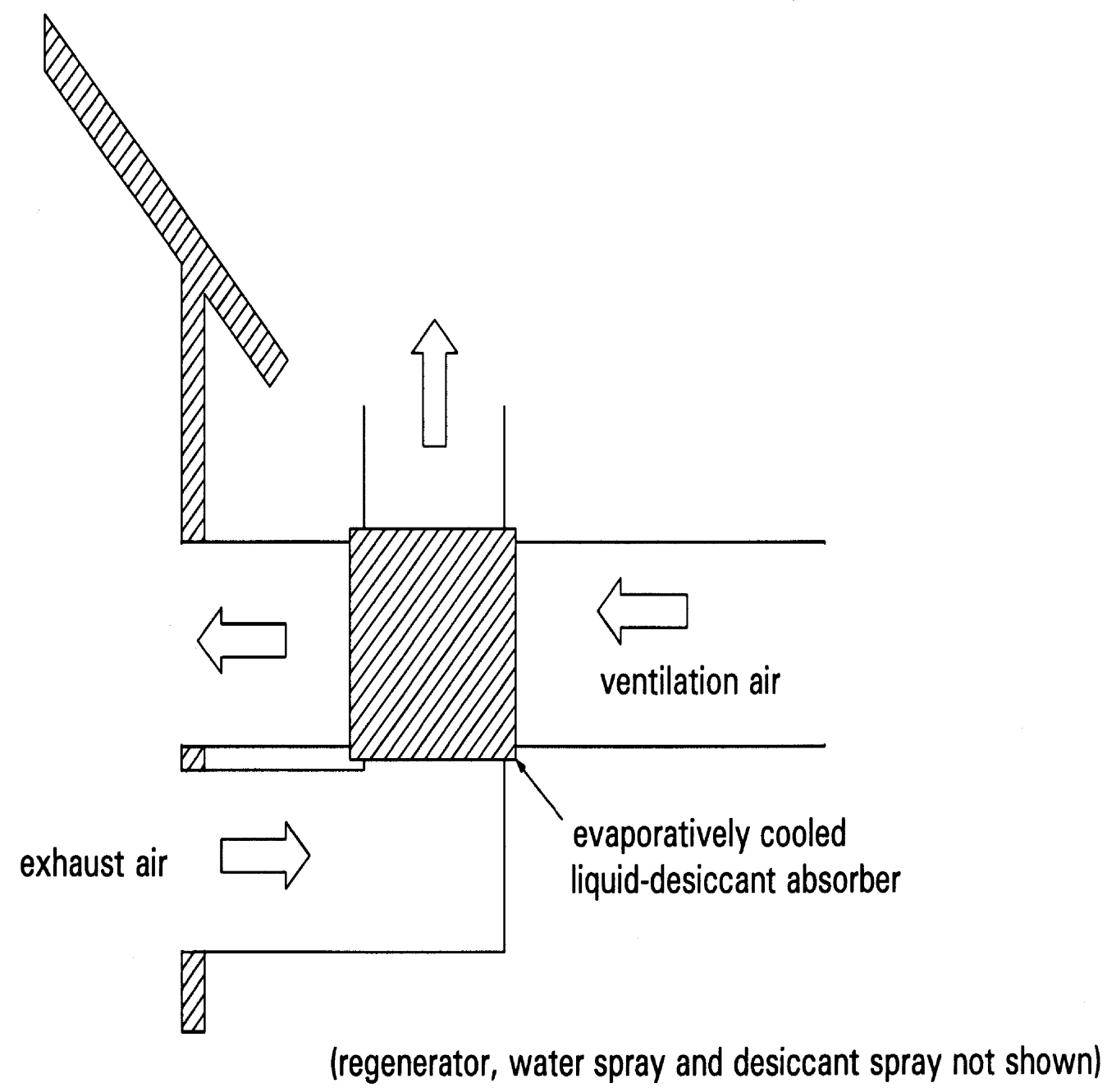

Figure 10. Schematic of an internally evaporatively cooled liquid-desiccant absorber for ventilation air.

The second, internally evaporatively cooled, absorber that was modeled is assumed to be constructed as a parallel-plate indirect evaporative cooler. The dimensions of this absorber are:

$\begin{array}{ll}\text { plate height } & 33^{\prime \prime} \\ \text { plate depth } & 33^{\prime \prime} \\ \text { number of plates } & 330 \\ \text { air gap process side } & 0.12^{\prime \prime} \\ \text { air gap cooling side } & 0.12^{\prime \prime} \\ \text { stack width } & 80^{\prime \prime}\end{array}$

The liquid-desiccant systems were modeled with both a single-effect and a double-effect regenerator. The single-effect regenerator assumes that the steam is vented to the atmosphere. The double-effect regenerator uses an evaporatively cooled condenser. Both systems use an $85 \%$ effective interchange heat exchanger.

The solid-desiccant system is assumed to be direct fired (i.e., a 100\% thermal efficiency for the gas burner). The liquid-desiccant system uses a gas boiler with a $83.5 \%$ efficiency. 
For both the solid-desiccant and liquid-desiccant systems, there is a trade-off between cooling capacity and COP. For the solid-desiccant system, the cooling capacity will increase but the COP will decrease as the regeneration temperature increases from $200^{\circ} \mathrm{F}$ to $300^{\circ} \mathrm{F}$. For the liquid-desiccant system, the cooling capacity will increase but the COP will decrease as the concentration of the desiccant entering the absorber increases from $30 \%$ to $40 \%$.

Figure 11 shows the performance of the preceding liquid-desiccant and solid-desiccant systems. For a liquiddesiccant system using either a single-effect or a double-effect regenerator, the evaporatively cooled absorber provides a moderate boost in cooling capacity, approximately $12 \%$, when the desiccant concentration is kept constant. This increase is due to the intimate physical proximity between the evaporative cooling and the absorption in the evaporatively cooled absorber. Rather than provide a fixed cooling water temperature at the absorber inlet which degrades throughout the absorber, the internally evaporatively cooled concept provides evaporative cooling at all locations within the absorber. The water cooled design would have to employ prohibitively high cooling water flowrates to duplicate this temperature sink profile. The use of a double-effect regenerator increases the COP of the liquid-desiccant system by between $50 \%$ and $100 \%$.

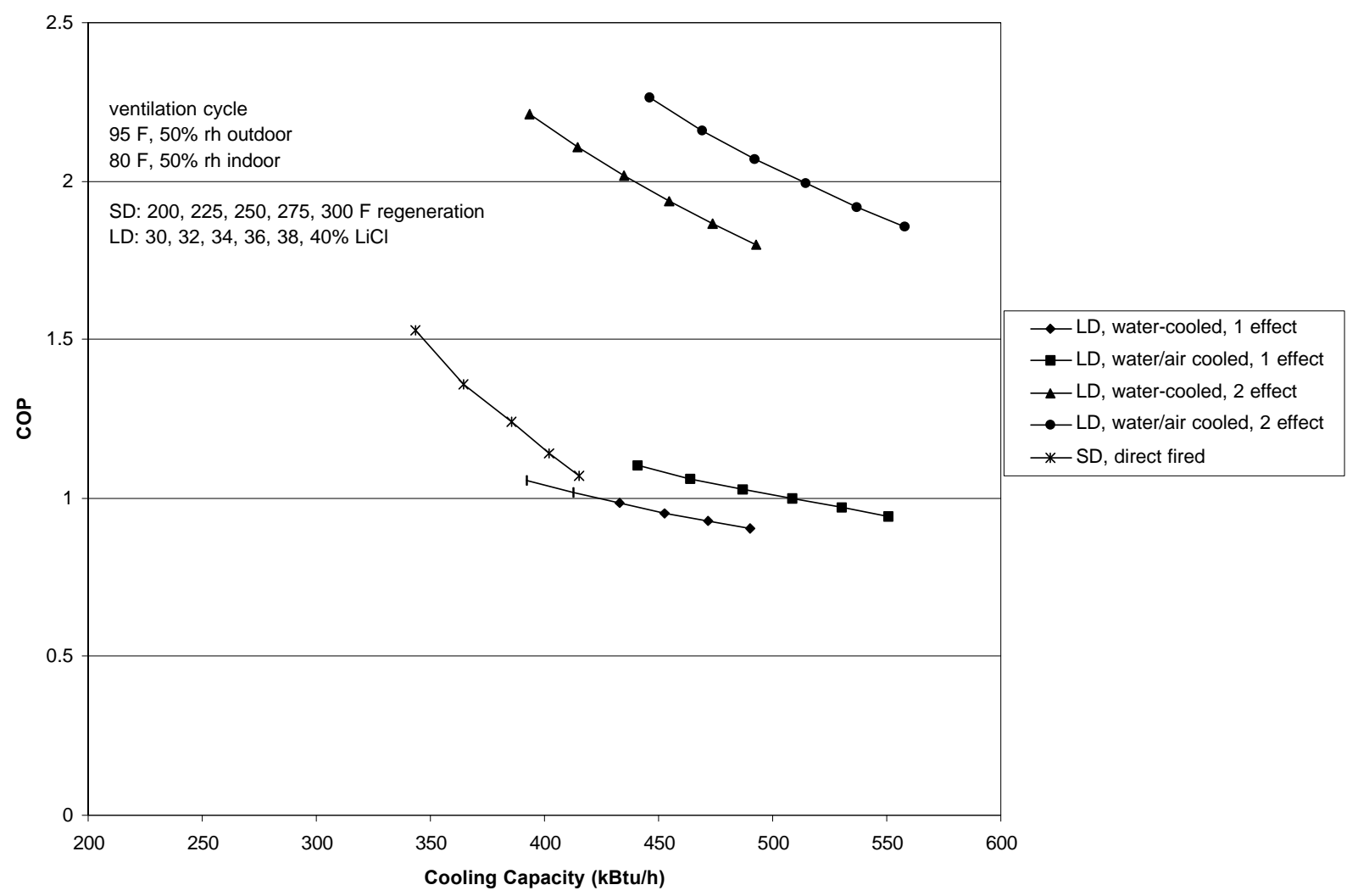

Figure 11. Comparative performance of liquid and solid-desiccant ventilation systems.

As shown in Figure 11, a solid-desiccant system with $260^{\circ} \mathrm{F}$ regeneration has about the same COP and capacity as a liquid-desiccant system with an evaporatively cooled absorber using a $26 \%$ lithium chloride solution and a single-effect regenerator (based on an extrapolation of the liquid-desiccant curve). At operating conditions that produce higher cooling capacities, the liquid-desiccant system has a moderately higher COP. This is significant because an effective way to bring down the cost of desiccant systems is to increase the cooling capacity of a fixed-geometry system. 
The liquid-desiccant systems that use the evaporatively cooled absorber have the highest cooling capacities. In these systems, the absorption process is continually cooled towards the wet-bulb temperature of the cooling air. This significantly increases the driving potential for heat and mass transfer.

Although the data does not appear in Figure 11, the cooling capacity of the liquid-desiccant system increases to about $580,000 \mathrm{Btu} / \mathrm{h}$ at a desiccant concentration of $43 \%$. This is about $40 \%$ higher than the cooling capacity of the solid-desiccant system operating at a $300^{\circ} \mathrm{F}$ regeneration temperature.

\section{Parasitic Power}

The two largest pressure drops in the solid-desiccant system occur across the desiccant rotor and the rotary heat exchanger. These pressure drops are approximately:

$\begin{array}{ll}\text { rotor process side } & 0.8 \text { in. } \mathrm{H}_{2} \mathrm{O} \\ \text { rotor regeneration side } & 1.2 \text { in. } \mathrm{H}_{2} \mathrm{O} \\ \text { heat exchanger } & 0.2 \text { in. } \mathrm{H}_{2} \mathrm{O}\end{array}$

Assuming a motor efficiency of 0.90 and a fan efficiency of 0.58 , the total blower power for the solid-desiccant system is 2.7 kilowatts $(\mathrm{kW})$. The motor drives for the rotor and heat exchanger draw an additional 300 watts $(\mathrm{W})$.

The blower power for the liquid-desiccant systems is lower than that for the solid-desiccant system. For the liquid-cooled absorber the major pressure drops are:

$\begin{array}{ll}\text { absorber (air side) } & 0.51 \text { in. } \mathrm{H}_{2} \mathrm{O} \\ \text { fluid cooler (air side) } & 0.51 \text { in. } \mathrm{H}_{2} \mathrm{O} \\ \text { absorber (fluid side) } & 5.0 \text { pounds per square inch (psi) } \\ \text { fluid cooler (fluid side) } & 5.0 \text { psi }\end{array}$

Assuming the same fan and motor efficiencies as used above and a pump efficiency of 0.6 , the total power for the system that uses the liquid-cooled absorber is $2.5 \mathrm{~kW}$.

When the evaporatively cooled absorber is used, the power goes down significantly. The pressure drops are:
absorber process side
0.38 in. $\mathrm{H}_{2} \mathrm{O}$
absorber cooling side
0.38 in. $\mathrm{H}_{2} \mathrm{O}$

and the blower power is $1.3 \mathrm{~kW}$.

The liquid-desiccant systems also need power to run the desiccant pumps and the pumps that flood the evaporatively cooled surfaces. For the low-flow absorbers used in both desiccant systems, the desiccant pump power is less than $100 \mathrm{~W}$. The water pump power is approximately $200 \mathrm{~W}$.

For both liquid-desiccant and solid-desiccant systems, additional air-side pressure drops occur across filters and saturators. The additional blower power to overcome these pressure drops is estimated to be $430 \mathrm{~W}$.

Using the solid-desiccant system's cooling capacity at $250^{\circ} \mathrm{F}$ and the liquid-desiccant system's cooling capacity at $40 \%$ lithium chloride (as shown in Figure 11), the energy efficiency ratios (EERs) for the three systems are:

solid-desiccant

liquid-desiccant/fluid-cooled absorber

liquid-desiccant/evap-cooled absorber
$112 \mathrm{Btu} / \mathrm{Wh}$

$153 \mathrm{Btu} / \mathrm{Wh}$

$275 \mathrm{Btu} / \mathrm{Wh}$ 
The very low parasitic power for the liquid-desiccant system that uses the evaporatively cooled absorber illustrates the advantage of using one component for both heat and mass exchange. For the solid-desiccant system, the entire process air must pass through the rotor where dehumidification occurs and then the heat exchanger where cooling occurs. This design will produce higher pressure drops than one in which the heat and mass transfer can occur in the same component.

\section{System First Cost}

Although it is beyond the scope of this project to prepare a detailed manufacturing cost estimate for the liquiddesiccant systems, some useful comparisons can be made. Based on previous work, the manufacturing cost for a 7,500 cfm liquid-desiccant absorber and fluid cooler is estimated to be [7]:

$\begin{array}{ll}\frac{\text { Liquid-cooled absorber }}{\text { material cost for plates }} & \$ 1,200 \\ \text { distributor, sump, pump } \$ 1,000 & \\ \text { labor } & \$ 2,600 \\ \text { total } & \$ 4,800\end{array}$

The manufacturing cost for the evaporatively cooled absorber will be significantly less because it contains much less material and there are fewer steps in its assembly. A rough estimate for this absorber is:

$\begin{array}{ll}\begin{array}{ll}\text { Evaporative-cooled absorber } \\ \text { material cost for plates }\end{array} & \$ 550 \\ \begin{array}{l}\text { distributor, sump, pump } \$ 1,000 \\ \text { labor }\end{array} & \$ 1,950 \\ \text { total } & \$ 3,500\end{array}$

Scaling up a manufacturing cost estimate for a 3-ton single-effect regenerator [4], gives a manufacturing cost for this component of $\$ 1,010$.

The manufacturing costs for the major components (i.e., the absorber and the regenerator) of a 7,500 cfm liquid-desiccant system will be approximately $\$ 5,810$ if the absorber is liquid-cooled, or $\$ 4,510$ if it is evaporatively cooled. These costs are equivalent to $\$ 0.77$ and $\$ 0.60$ per cfm of process air.

It is very difficult to obtain manufacturing costs for the major components of a solid-desiccant system. Retail costs for rotors are on the order of $\$ 2.00$ per cfm and rotary heat exchangers, $\$ 1.00$ per $\mathrm{cfm}$. For a multiplier of 2.5 between manufacturing and retail costs, the solid-desiccant rotor and heat exchanger would have a combined manufacturing cost of $\$ 1.20 \mathrm{per} \mathrm{cfm}$. This is twice as high as the $\$ 0.60$ per $\mathrm{cfm}$ for the evaporatively cooled absorber and regenerator. 


\section{Operating Costs}

The results of a simple "ball park" analysis of the operating costs for the solid-desiccant and liquid-desiccant systems (evaporatively cooled absorber only) are given below. The analysis assumed a warm, humid location where cooling of the ventilation air is required for most of the year when the building is occupied, i.e., the ventilation units run for 2,500 hours. The total cooling provided during these 2,500 hours is assumed to be equivalent to 1,000 hours of cooling at the full-load conditions shown in Figure 11. The solid-desiccant system operates at a $250^{\circ} \mathrm{F}$ regeneration temperature and the liquid-desiccant system operates at a $40 \%$ lithium chloride concentration. With these assumptions, the seasonal energy use for the two systems is:

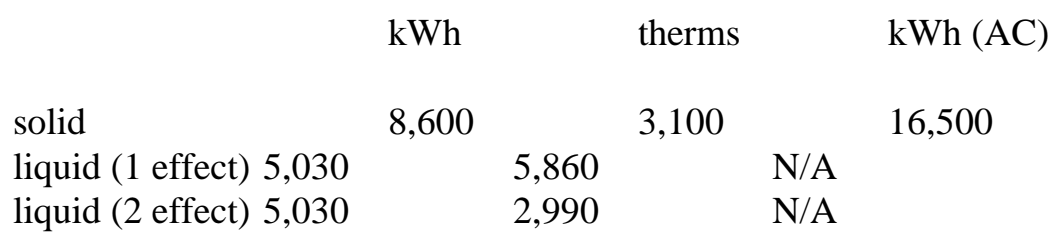

In the preceding table, the solid-desiccant system has an entry in the column with the heading "kWh (AC)". Because the liquid-desiccant systems have a significantly higher cooling rate at design-day conditions-550 $\mathrm{kBtu} / \mathrm{h}$ versus $385 \mathrm{kBtu} / \mathrm{h}$ for the solid-desiccant system-they will more effectively shift load off of the building's central cooling system. The entry for "kWh (AC)" is the additional electricity to run the building's central cooling system assuming it has an EER of 10.0.

For gas at $\$ 0.62$ per therm and electricity at $\$ 0.084$ per $\mathrm{kWh}$, the total seasonal costs are:

solid $\$ 4,030$

liquid (1 effect) $\$ 4,055$

liquid (2 effect) $\$ 2,280$ 


\section{A Comparison of a Liquid-Desiccant System and a Conventional Vapor-Compression System Processing Recirculation Air}

Although the cooling and dehumidification of ventilation air is an important market, desiccant systems will have a far greater impact on the country's energy use if they can compete with electric vapor-compression systems in the much larger recirculation-air market. Unfortunately, "competitiveness" is difficult to quantify, particularly for a novel technology that has not yet been commercialized. However, because it is usually assumed that desiccant systems are not competitive in the recirculation-air market, it would be most useful to study whether the enhancements offered by advanced liquid-desiccant systems can make them competitive and under what conditions.

The assumptions for the following analysis are:

- The liquid-desiccant system uses an internally evaporatively cooled absorber and a double-effect regenerator with a $83.5 \%$ efficient boiler

- Cycling losses that will occur in both systems are ignored

- The target building has a linear load curve; the cooling load when the outdoor temperature is $20^{\circ} \mathrm{F}$ higher than the indoor temperature is $120,000 \mathrm{Btu} / \mathrm{h}$; the load goes to zero when the outdoor temperature is $7^{\circ} \mathrm{F}$ below the indoor temperature

- The target building is in Atlanta, Georgia; TMY2 weather data applies

- Indoor conditions are constant at $78^{\circ} \mathrm{F}$ and $50 \%$ rh

- Fans operate only while the vapor-compression or liquid-desiccant systems are providing cooling (i.e., no continuous fan operation).

The liquid-desiccant system is modeled using two control strategies. In the first, the desiccant concentration entering the absorber is kept constant at $43 \%$ (which is about the highest value allowed before crystallization problems arise). In the second, the desiccant concentration is adjusted each hour to the lowest value that allows the system to meet the load on the building for that hour. The desiccant concentration is not allowed to go below $23 \%$.

The vapor-compression system is modeled using performance maps provided by the Trane Company in LaCrosse, Wisconsin (Trane publication number 22-1621-04-1296 [EN]) for a very high efficiency, 13.45 seasonal energy efficiency ratio ( SEER) unit.

The seasonal load on the building is $74,400 \mathrm{kBtu}$. The electric and gas consumption for the three competing systems is:

$\begin{array}{lcl} & \underline{\mathrm{kWh}} & \underline{\text { therms }} \\ \text { electric vapor-compression } & 5,450 & \mathrm{~N} / \mathrm{A} \\ \text { liquid-desiccant }(43 \%) & 620 & 565 \\ \text { liquid-desiccant (variable) } & 1,520 & 383\end{array}$

Based on these results, the operating cost of the liquid-desiccant system with constant desiccant concentration is equal to the operating cost of the vapor-compression system when the ratio of gas-to-electric costs (based on energy) is $0.117 \$ / \mathrm{kWh} / \$ /$ therm. For the liquid-desiccant system with variable concentration, operating 
costs are equal at a ratio of $0.098 \$ / \mathrm{kWh} / \$ /$ therm. As a reference, the national average gas and electric prices-\$0.084 per $\mathrm{kWh}$ and $\$ 0.62$ per therm-are equivalent to an gas-to-electric cost ratio of 0.136 $\$ / \mathrm{kWh} / \$ /$ therm. Because this value is higher than the preceding values (i.e., electricity is more expensive than the "break-even" value), one would expect the desiccant systems to have a significantly lower operating cost in most of the country.

The desiccant system is also likely to use less primary energy than the electric vapor-compression system. In the preceding example, primary energy use will be equal for the two systems when the overall efficiency for generating, transmitting, and distributing electricity is $35 \%$. Because almost all electricity now generated has a much lower "coal pile to end use" efficiency than $35 \%$, the liquid-desiccant system has the potential to reduce national energy use.

The seasonal COPs and EERs for the preceding three options are:

$\begin{array}{lcc} & \text { EER } & \text { COP } \\ \text { electric vapor-compression } & 13.7 & \text { N/A } \\ \text { liquid-desiccant }(43 \%) & 120.0 & 1.32 \\ \text { liquid-desiccant (variable) } & 48.9 & 1.92\end{array}$

First cost is often more important than operating cost when an HVAC system is purchased. Griffiths roughly estimates the manufacturing cost for a 7,500-cfm ventilation-air liquid-desiccant syste in a report to GRI [5 ]. The cost estimate for the evaporatively cooled absorber in this earlier work, expressed in dollars per ton, applies to the recirculation-air system. However, the ventilation-air system used a relatively inexpensive single-effect regenerator. This must be replaced with a double-effect regenerator if the liquid-desiccant system is to have lower operating costs.

Absorption systems provide a useful starting point for estimating the cost to manufacture a double-effect regenerator. As shown in the following breakdown, which is based on an estimate of the manufacturing cost for a 25-ton absorption chiller, the costs for the generator and recuperators (interchange heat exchanger) are a major fraction of the absorption system's total cost [8].

In Table 3, all components except those followed by a star would be needed in a liquid-desiccant air conditioner and would have to be modified to account for different operating conditions and the use of lithium chloride instead of lithium bromide. The starred components- the evaporator, absorber and absorber/ evaporator vessel-would be replaced by the evaporatively cooled absorber in the liquid-desiccant air conditioner. The starred components have a material cost of $\$ 925$. Their total cost, $\$ 1,900$, is about $20 \%$ of the cost for the complete system.

The material cost for an internally cooled absorber for a 25-ton liquid-desiccant air conditioner would be about $\$ 730$ (scaled up from the cost in Feldman's report to GRI [4]). While this is moderately lower than the material cost for the absorption components that would be replaced, the impact on the total system cost is relatively small.

Other factors that will tend to increase or decrease the cost of the liquid-desiccant air conditioner relative to the absorption system include the following:

- Much of the massive structure required to support the large absorber, evaporator, and vacuum shell of the absorption system will not be needed for the liquid-desiccant system.

- The liquid-desiccant regenerator will have to purge a much larger volume of non-condensibles from the condenser. 
Table 3. Liquid Desiccant Air Conditioner Components

\begin{tabular}{|c|c|c|c|c|}
\hline Component & Weight (Ib) & Material (\$) & Labor (\$) & Total (\$) \\
\hline 1st-effect generator & 75 & 650 & 300 & 950 \\
\hline 2nd-effect generator & 120 & 175 & 350 & 525 \\
\hline Condenser & 130 & 290 & 190 & 480 \\
\hline Evaporator* & 200 & 375 & 275 & 650 \\
\hline Absorber* & 300 & 560 & 450 & 1010 \\
\hline High-T recuperator & 180 & 75 & 350 & 425 \\
\hline Low-T recuperator & 180 & 75 & 350 & 425 \\
\hline Generator vessel & 200 & 60 & 100 & 160 \\
\hline Absorber/evap. vessel ${ }^{*}$ & 300 & 90 & 150 & 240 \\
\hline Pumps & & 750 & & 750 \\
\hline Controls/wiring/etc. & & 800 & 300 & 1100 \\
\hline Purge, piping, structure & 500 & 500 & 700 & 1200 \\
\hline $\begin{array}{l}\text { Lithium bromide charge, } \\
\text { assembly }\end{array}$ & & 600 & 1100 & 1700 \\
\hline Totals & 2185 & $\$ 5000$ & $\$ 4615$ & $\$ 9615$ \\
\hline
\end{tabular}

*Not required for a liquid-desiccant air conditioner.

- The liquid-desiccant regenerator will require pumps to move strong desiccant and condensate out of the low-pressure stage.

- The cost per pound for lithium chloride is about half that for lithium bromide.

The preceding analysis shows that the cost for the regenerator and recuperators is a major part of the total cost for a liquid-desiccant air conditioner that uses a double-effect regenerator. Furthermore, the manufacturing cost for the liquid-desiccant system will be comparable to the cost for a 25 -ton absorption chiller. This manufacturing cost is $\$ 385$ per ton. If one assumes a relatively large (2.5) multiplier, which reflects the low initial sales for the desiccant system, its retail cost is $\$ 965$ per ton.

At $\$ 965$ per ton, the liquid-desiccant air conditioner will have a significantly higher first cost than the competing electric vapor-compression system. This is not surprising considering that electric air conditioners have been maturing for over 50 years and the desiccant system is a prototype.

Compared to other small, gas-fired cooling systems, the first cost for the liquid-desiccant system is much more competitive. A small engine-driven heat pump, such as the York Triathlon, costs between $\$ 1,000$ and $\$ 1,400$ per ton. A small double-effect absorption system such as one made by Yazaki cost about $\$ 1,000$ per ton. 


\section{References}

1. "Liquid Desiccant Dehumidifier," project summary published by Arthur D. Little, Inc. (ADL), Cambridge, MA 02140 (available from David McFadden ADL, or Ray Albrecht, NYSERDA).

2. Lowenstein, A.I., "The Effect of Material Properties on the Performance of Liquid-Desiccant Air Conditioners and Dehumidifiers," Final Report, GRI-93/0253, April 1993.

3. Lowenstein, A.I., et al., "Integrated Gas-Fired Desiccant Dehumidification Vapor-Compression Cooling System for Residential Applications," GRI Phase I final report, GRI-88/0326, November 1988.

4. Feldman, S., et al., "Integrated Gas-Fired Desiccant Dehumidification Vapor-Compression Cooling System for Residential Applications," GRI Phase III final report, GRI-92/0304, December 1991.

5. Griffiths, W., "The Development of a Humidity Pump," GRI unpublished report (contact author for reference).

6. Collier, R.K., "Desiccant Dehumidification and Cooling Systems: Assessment and Analysis," Draft report prepared for Office of Building Equipment, U.S. Department of Energy, November, 1996.

7. Internal studies performed at AIL Research, Inc.

8. Leigh, R.W., et al., "Cost Reductions in Absorption Chillers, Phase II," BNL 42502, GRI-89/0049, February 1989. 


\section{Appendix A}

\section{Additional Technology Issues and Opportunities for Further Advancing Liquid-Desiccant Systems}

\section{Vapor-Compression Distillation for Desiccant Regeneration}

Another technology that can be used to increase the efficiency of separation processes is vapor-compression distillation (VCD). As shown in Figure A.1 on page A-2, the latent energy in the low pressure steam that leaves a boiler can be returned to the boiler if the steam is compressed to a sufficiently high pressure.

For a liquid-desiccant regenerator, VCD will be effective only if the compressor is driven by a gas-fired engine and the waste heat from the engine can be recovered for heating the desiccant. The efficiency of a VCD regenerator falls off significantly as the desiccant concentration (and, hence, the boiling point elevation) increases. Typical values for regeneration COP would be: ${ }^{2}$

$\begin{array}{cc}\text { Concentration } & \text { COP } \\ 33 \% & 2.6 \\ 35 \% & 2.3 \\ 37 \% & 2.0 \\ 39 \% & 1.8 \\ 41 \% & 1.6 \\ 43 \% & 1.4\end{array}$

\section{An Engine-Driven Heat Pump Combined with a Liquid-Desiccant Air Conditioner}

Liquid-desiccant systems can be coupled with engine-driven heat pumps or chillers to create a high efficiency cooling system. In this combined system, waste heat from the engine is used to regenerate the desiccant.

Combined cooling systems have been explored in the past. Tecogen studied the possibility of using the waste heat from one of their engine-driven chillers to run an absorption system. Although this combination does not appear economically viable, several factors improve the feasibility of an engine/liquid-desiccant system:

- The desiccant system's regenerator will be more efficient than an absorption system's generator when operating on low-temperature heat (i.e., heat available at less than $220^{\circ} \mathrm{F}$ ).

- The cooling components for the liquid-desiccant system are smaller, lighter, and less expensive than those for the absorption system.

- The desiccant system does not have to match the operation of the engine to its operation; desiccant can be regenerated and stored for later use.

The Trane Triathlon engine-driven heat pump with its 0.9 COP at ARI summer conditions can be used as an example. At these conditions, the system consumes 40,000 Btu/h of gas and delivers 36,000 Btu/h of cooling. Approximately, $24,000 \mathrm{Btu} / \mathrm{h}$ of waste heat are available at a temperature above $200^{\circ} \mathrm{F}$. This heat can be used by the liquid-desiccant system to regenerate desiccant at a COP of 0.6. If the liquid-desiccant system's absorber operates isothermally (i.e., it provides only latent cooling), then the system's cooling COP will equal the regenerator's COP. Under these conditions, the liquid-desiccant system will increase the total 
DESUPERHEATER

INTERCHANGER

strong desiccant

weak desiccant
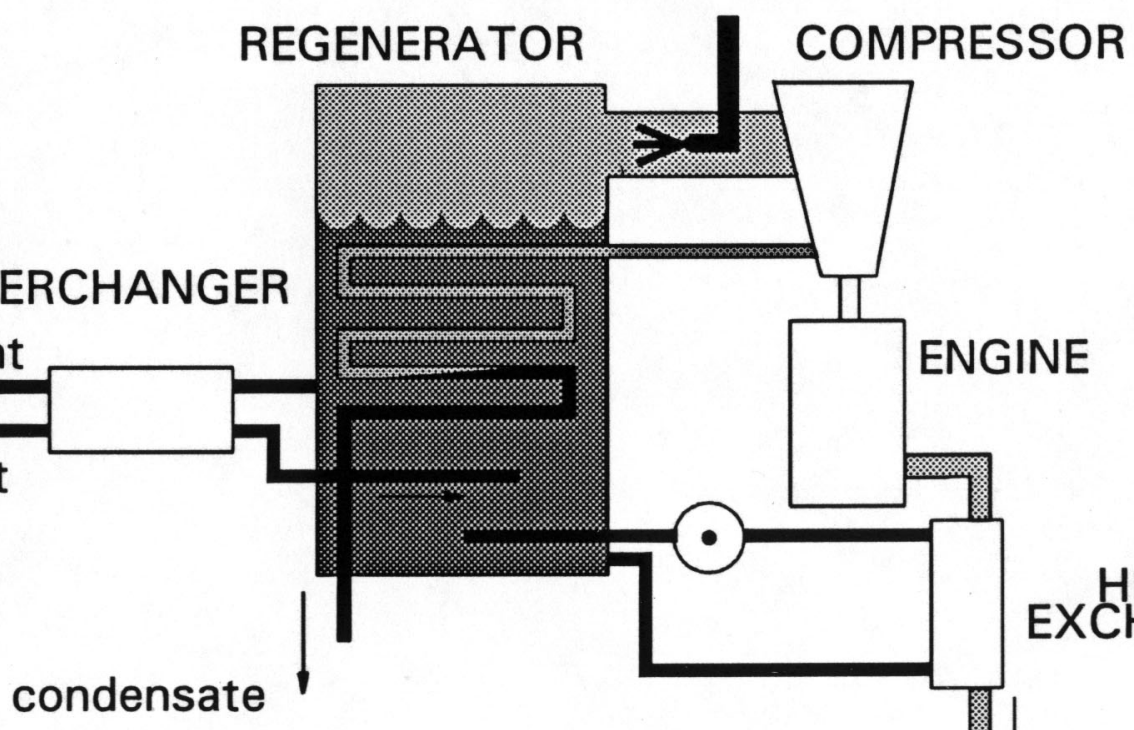
EXCHEATGER

exhaust 
cooling COP from 0.9 to 1.26. The seasonal performance of the combined desiccant/engine cooling system can be further increased by using the desiccant system's absorber to provide "free" evaporative cooling during periods when the outdoor wet-bulb temperature is low.

\section{A Geothermal Liquid-Desiccant Air Conditioner}

In many parts of the Northeast and upper Midwest, ground water temperatures never rise above the high 50s. While water at this temperature could effectively cool an entire building without a separate dehumidifier, conditions in the building would be very uncomfortable. Thus, except in applications where ground water is used to cool the condenser of a geothermal heat pump, the potential energy savings from using ground water for cooling has not been realized.

A liquid-desiccant system provides a way to more fully exploit geothermal cooling. Using ground water to cool the absorber, a liquid-desiccant air conditioner can provide adequate sensible and latent cooling with electricity needed only for the circulating pump and fans. No other energy source is needed.

A geothermal liquid-desiccant air conditioner is shown in Figure A.2 on page A-4. It consists of the following three components that process the air in series: (1) an adiabatic desorber, (2) a ground-water-cooled heat exchanger, and (3) a ground-water-cooled absorber. The water gained by the desiccant in the absorber equals that lost in the desorber, so there is no need for a separate regenerator.

The psychometric chart in Figure A-3, on page A-5, shows the performance of a geothermal liquid-desiccant air conditioner that processes air at $80^{\circ} \mathrm{F}$ with $50 \%$ rh (i.e., ARI test conditions) and with ground water at $58^{\circ} \mathrm{F}$ (which is typical of southern New England in the summer). Because the absorber is drying very humid air, the desiccant can be very weak. In this example, a $16 \%$ to $17 \%$ lithium chloride solution is used. However, other salt-based desiccants and glycols (if the carryover of glycol is acceptable) could be used.

In the preceding example, the geothermal liquid-desiccant air conditioner provides cooling at $490 \mathrm{cfm} / \mathrm{ton}$. This value, although slightly higher than the $400 \mathrm{cfm} /$ ton that is typical of a conventional system, should not cause any significant implementation problems.

In regions of the country where ground water temperatures are too high for the geothermal liquid-desiccant air conditioner to provide sufficient cooling, the system can be augmented with either a gas-fired regenerator or a solar regenerator. Because most of the ground water temperatures in the country are lower than air wetbulb temperatures on summer design days, the geothermal liquid-desiccant air conditioner will have better performance characteristics than a liquid-desiccant system that uses evaporative cooling.

\section{A Desiccant-Enhanced Evaporative Cooler}

Geothermal liquid-desiccant air conditioners would not be effective in the southwestern United States. Ground water temperatures, which are approximately equal to the seasonal mean air temperature, are quite high.

Furthermore, the low humidity in this part of the country keeps wet-bulb air temperatures relatively low. Under these conditions, a liquid-desiccant air conditioner will be most effective if it is evaporatively cooled.

Perhaps the most useful way to view a liquid-desiccant air conditioner designed for the Southwest is as an indirect evaporative cooler that is augmented with desiccant. In this part of the country, an indirect evaporative cooler will adequately cool a building for most of the year. For example, in Phoenix, Arizona, the 2\% "humidity" design point (i.e., conditions exceeded 175 hours per year) has a wet-bulb temperature of $75^{\circ} \mathrm{F}$. This "sink" temperature is much too high to effectively cool a building. 


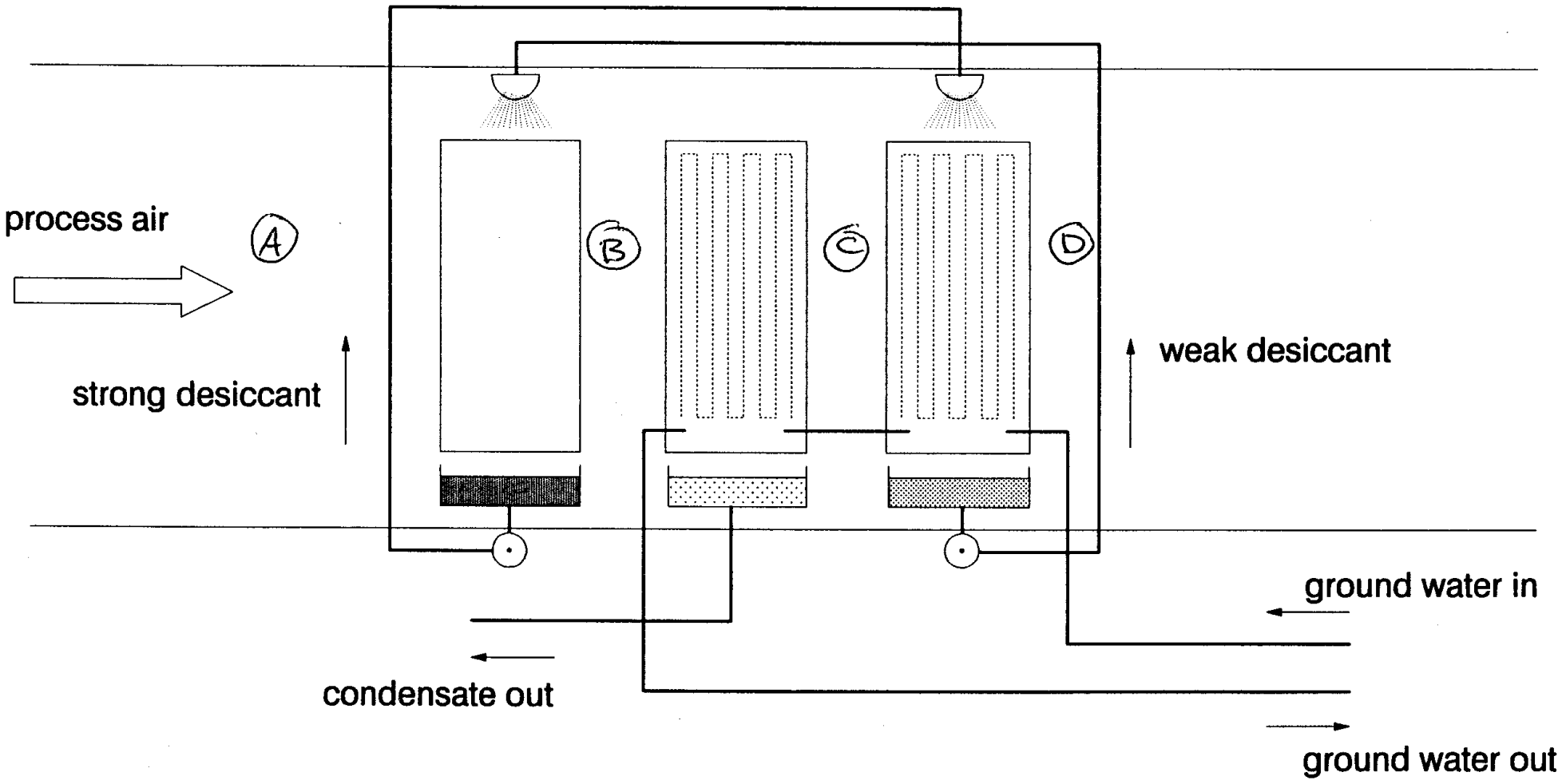


50

55

35
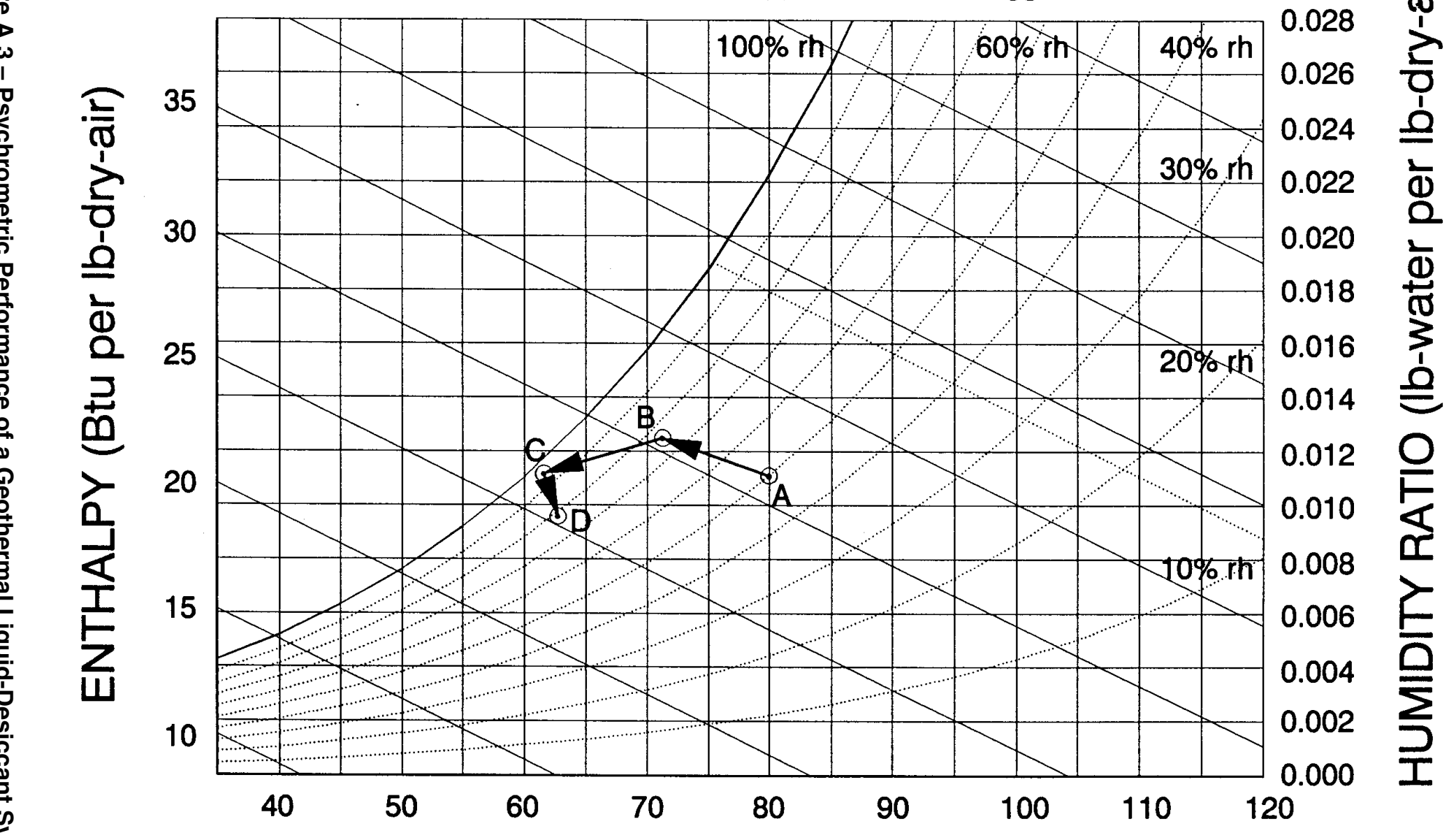

$40 \% \mathrm{rh}$

0.028

등

DRY BULB TEMPERATURE (F) 
How can a desiccant augment the performance of an indirect evaporative cooler? Heat is released when water vapor is absorbed by the desiccant. If one were to adiabatically dehumidify air so that the desiccant and air achieved equilibrium, the air would heat up to a temperature that is a function of its initial enthalpy and the concentration of the desiccant. This unique temperature is referred to as the brine-bulb temperature. (The reference to "brine-bulb" is an analogy to the adiabatic cooling of air in a saturator towards its wet-bulb temperature.) Using a $40 \%$ lithium chloride solution, air at ARI indoor conditions $\left(80^{\circ} \mathrm{F}, 0.011 \mathrm{lb} / \mathrm{lb}\right)$ will have a brine-bulb temperature of $99^{\circ} \mathrm{F}$. Just at the wet-bulb temperature is the driving potential for heat flow in evaporatively cooled processes, the brine-bulb temperature is the driving potential for heat flow in a desiccant dehumidification process.

The enhanced cooling capacity from adding a liquid desiccant to an indirect evaporative cooler is best illustrated by a modeled cross-flow air-to-air heat exchanger with 2.72 NTUs (for balanced airflows, this heat exchanger would have a $66 \%$ effectiveness.) Figure A.4 presents the cooling capacity expressed as cfm per ton as a function of outdoor wet-bulb temperature for the preceding heat exchanger operating as an indirect evaporative cooler and as an evaporatively cooled liquid-desiccant absorber. Both systems operate well at a wet-bulb temperature of $60^{\circ} \mathrm{F}$. The indirect evaporative cooler provides cooling at $630 \mathrm{cfm} / \mathrm{ton}$ while the liquid-desiccant absorber ranges from 310 to $420 \mathrm{cfm} /$ ton, depending on the desiccant concentration. (As a reference, a conventional vapor-compression system at its rating conditions typically processes about $400 \mathrm{cfm}$ of air per ton of cooling. The lower the cfm-per-ton the better, the size of the cooling system can be reduced.)

As shown in Figure A.4 on page A-7, the indirect evaporative cooler's capacity quickly degrades (i.e., higher values of $\mathrm{cfm}$ per ton) as the wet-bulb temperature rises above $65^{\circ} \mathrm{F}$. However, by using a $40 \%$ lithium chloride solution in the absorber, the cooling capacity of the desiccant system can be kept relatively high even at the $2 \%$ design conditions for Phoenix (i.e., $75^{\circ} \mathrm{F}$ wet-bulb temperature).

\section{A Solar Liquid-Desiccant Air Conditioner}

Desiccant systems are one of several heat-actuated technologies that provide cooling. Although these heatactuated technologies have been considered as part of a solar cooling system, absorption systems have received the most attention. A solar/absorption system manufactured by Arkla did reach the market, but sales were very poor.

A solar liquid-desiccant air conditioner will have the following important advantages over its absorption counterpart.

- An internally cooled liquid-desiccant absorber will be much less expensive than the absorber/evaporator and cooling tower that it would replace in an absorption system.

- The liquid-desiccant system will operate more efficiently at the relatively low temperatures provided by solar thermal collectors (as described in a preceding section, the strong solution in a liquid-desiccant system has a boiling point that is $30^{\circ} \mathrm{F}$ less than that for the strong solution in an absorption system.

- By incorporating evaporative cooling into the absorber, a liquid-desiccant system can provide a modest fraction of its total cooling as sensible. Because this sensible cooling occurs without the desiccant absorbing water vapor, the regeneration that must be provided by the solar collectors is less (i.e., smaller collectors).

- It is practical to store moderate amounts of strong lithium chloride solution so the "mismatch" between when solar energy is available and when cooling is needed can be more easily accommodated. 


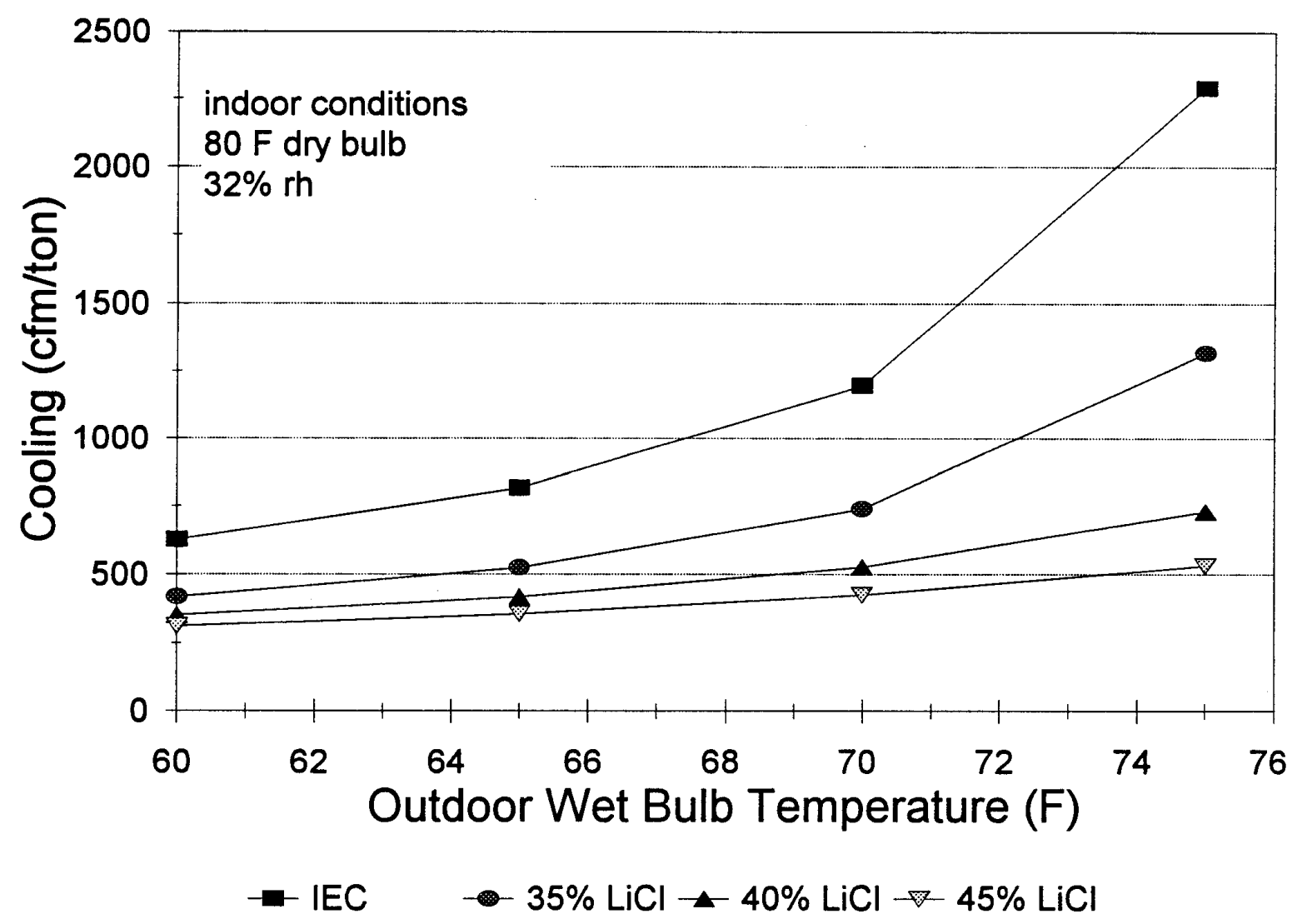

Figure A.4 - Comparative Performance of Indirect Evaporative Cooler and Liquid Desiccant System at Different Outdoor Wet-Bulb Temperatures 
An important characteristic of liquid-desiccant systems is that in dry climates, such as the Southwest, regeneration can effectively occur at temperatures provided by unglazed collectors. In fact, there will be times when outdoor air can regenerate the liquid desiccant without additional heat input.

To understand how a desiccant can be regenerated without heat input, one must realize that a desiccant at a constant concentration will achieve equilibrium with air at an approximate constant relative humidity over a broad temperature range. This is illustrated in Figure A.5 on page A-9. In this figure, the four dotted lines that curve upward follow the humidity of air that is in equilibrium with a lithium chloride solution at $32 \%$, $36 \%, 40 \%$ and $44 \%$ concentrations. Although they diverge slightly, they closely follow lines of constant relative humidity.

A $43 \%$ lithium chloride solution, which is strong enough to provide adequate cooling on a design-day in the Southwest, will desorb water (i.e., it will be regenerated) when it comes into contact with air at a relative humidity that is less than $15 \%$ in Phoenix, the relative humidity of the outdoor air will be less than $15 \%$ for approximately 1,000 hours each year. In theory, a lithium chloride could be regenerated to at least a $43 \%$ concentration during these 1,000 hours with no energy other than that needed to run pumps and fans. (In practice, the driving potential for desorption may be too small to permit the use of a reasonably sized regenerator.)

By moderately boosting the temperature of either the air or the desiccant, the number of hours that desorption occurs, can be greatly increased. If the desiccant were heated $30^{\circ} \mathrm{F}$ above ambient temperatures, which is within the range of an unglazed collector, the number of hours when desorption occurs would increase to about 5,800 , or about $66 \%$ of the year.

The preceding analysis shows the potential viability of a low-cost solar cooling system using unglazed collectors and a liquid-desiccant absorber in the hot, dry climates. A more detailed analysis is needed to determine the design and operating characteristics of this solar cooling system. Also, more work is needed to determine the geographic regions in which it would be competitive with alternative cooling technologies.

\section{Desiccant Storage}

Unlike absorption and vapor-compression systems in which the strong absorbent or liquefied refrigerant must be used as it is produced, the production of strong desiccant can be "decoupled" from the cooling effect. This allows the regenerator to be sized for less than "peak load" operation.

A preliminary study showed that too much lithium chloride would be needed to completely "levelize" the regenerator's operation. For a home that has a design-day cooling load of three tons and a maximum 24-hour load of 400,000 Btu, approximately 50 gallons of lithium chloride solution would be needed if the regenerator was sized to meet an average load of $16,700 \mathrm{Btu} / \mathrm{h}$ rather than a peak load of $36,000 \mathrm{Btu} / \mathrm{h}$. The cost for the lithium chloride would be $\$ 590$, or about $\$ 200$ per ton of peak cooling.

Although it may not be practical to completely "levelize" the operation of the regenerator, there may be an economical trade-off between the size of the regenerator and the amount of desiccant storage. A more detailed analysis would be needed to identify the optimum amount of storage. Storage could be more effectively used to reduce the size of the regenerator if the liquid desiccant was less expensive. Unfortunately, the less expensive candidates do not perform as well as lithium chloride.

The least expensive alternative to lithium chloride is calcium chloride. Unfortunately, calcium chloride is a relatively weak desiccant. A $42 \%$ solution, which is about as strong as can be used without encountering crystallization, will dry air to about $35 \%$ rh. (For comparison, a $43 \%$ lithium chloride solution can dry air to a $15 \%$ rh.) 


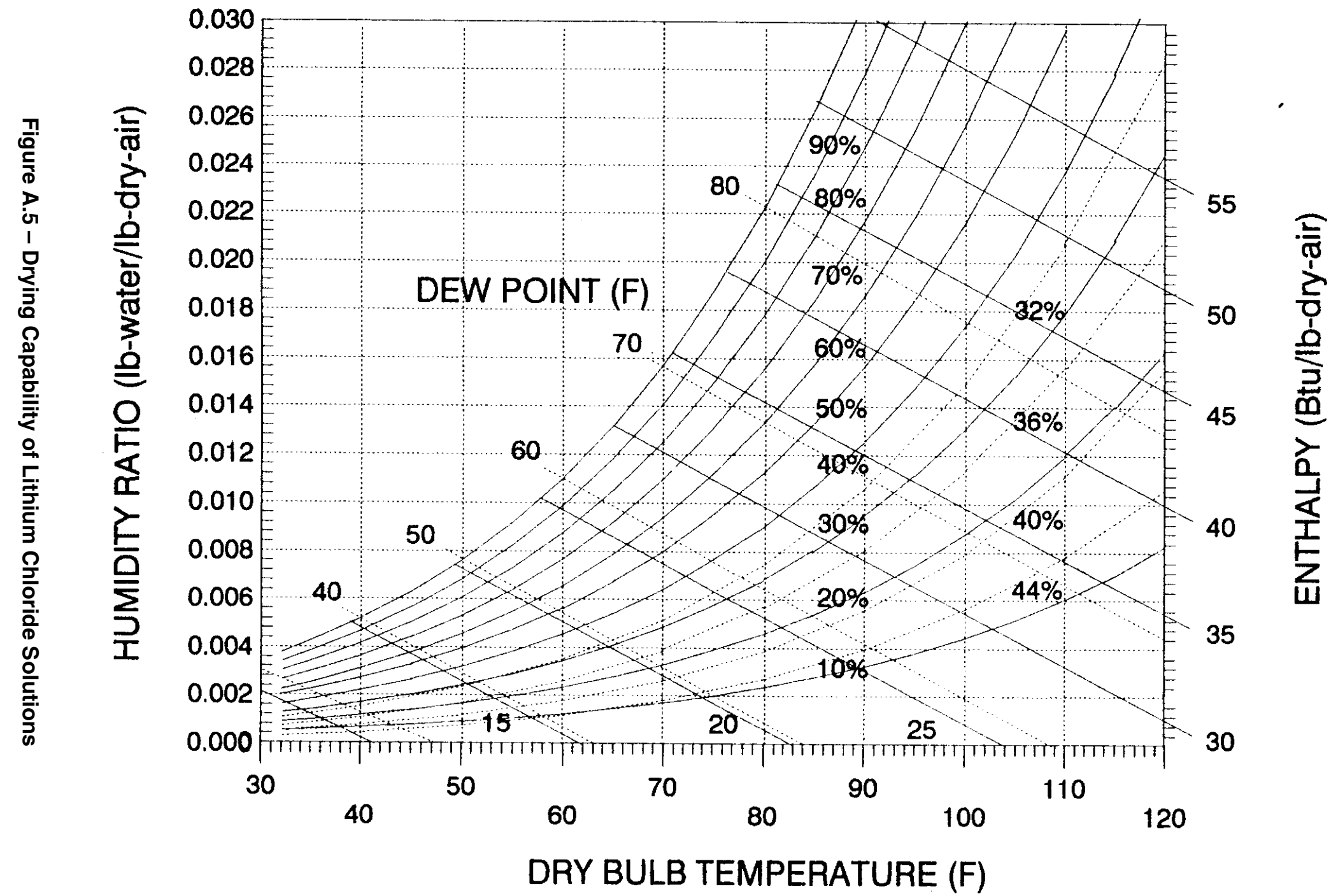


Another less expensive alternative is potassium acetate. While potassium acetate could dry air to about $25 \%$, its viscosity becomes very high. At $70 \%$ concentration and $80^{\circ} \mathrm{F}$, a potassium acetate solution has a viscosity of about $28 \mathrm{cp}$. This is almost twice has high as a $43 \%$ lithium chloride solution at the same temperature. Water at $80^{\circ} \mathrm{F}$ has a viscosity of close to 1.0 .

A more detailed analysis is needed to identify applications where a less expensive (and weaker) desiccant than lithium chloride could be used. These applications will be good candidates for using storage to reduce the cost of the regenerator. 


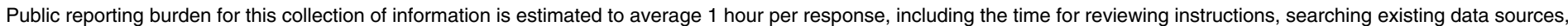

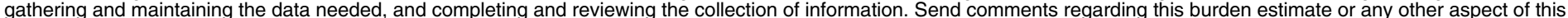

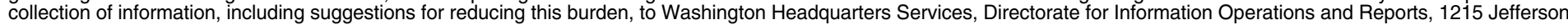

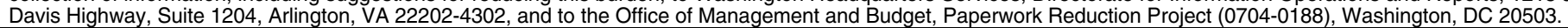

\begin{tabular}{l|l|l|l}
\hline $\begin{array}{l}\text { 1. AGENCY USE ONLY (Leave } \\
\text { blank) }\end{array}$ & $\begin{array}{l}\text { 2. REPORT DATE } \\
\text { November } 1998\end{array}$ & $\begin{array}{l}\text { 3. REPORT TYPE AND DATES COVERED } \\
\text { Technical Report }\end{array}$ \\
\hline
\end{tabular}

4. TITLE AND SUBTITLE Advanced Commercial Liquid-Desiccant Technology Development Study

6. AUTHOR(S)

Steven Slayzak, Joe Ryan, Ahmad Pesaran, and Andy Lowenstein

7. PERFORMING ORGANIZATION NAME(S) AND ADDRESS(ES)

National Renewable Energy Laboratory

1617 Cole Boulevard

Golden, Colorado 80401-3393

9. SPONSORING/MONITORING AGENCY NAME(S) AND ADDRESS(ES)

U.S. Department of Energy

1000 Independence Ave., SW

Washington, D.C. 20585
5. FUNDING NUMBERS

BE703001

BE903001
8. PERFORMING

ORGANIZATION REPORT

NUMBER TP-550-24688

10.

SPONSORING/MONITORING

AGENCY REPORT

NUMBER

\section{SUPPLEMENTARY NOTES}

12a. DISTRIBUTION/AVAILABILITY STATEMENT

12b. DISTRIBUTION CODE

National Technical Information Service

U.S. Department of Commerce

5285 Port Royal Road

Springfield, VA 22161

13. ABSTRACT (Maximum 200 words) The objective of this report is to provide information to help DOE plan its future activities on liquid-desiccant technologies. The report meets this objective by (1) identifying commercial and residential markets where the liquiddesiccant systems will first be most successful and (2) identifying advances in the individual components of a liquid-desiccant system that will allow it to expand into new markets.
14. SUBJECT TERMS
15. NUMBER OF PAGES

Desiccant, liquid-desiccant, desiccant cooling technologies, dehumidification, ventilation

16. PRICE CODE

\section{SECURITY CLASSIFICATION OF REPORT}

\section{SECURITY CLASSIFICATION OF THIS PAGE}

19. SECURITY CLASSIFICATION

OF ABSTRACT
20. LIMITATION OF ABSTRACT 